\title{
Video Streaming over 802.11b in the Presence of Fading due to Human Traffic and Bluetooth Interference
}

\author{
by \\ Karma Kelzang Eudon \\ B.E. in Electrical and Electronics Engineering, Vellore Institute of \\ Technology (Madras University)

\section{A THESIS SUBMITTED IN PARTIAL FULFILLMENT OF THE REQUIREMENTS FOR THE DEGREE OF}

\section{Master of Science in Engineering} \\ In the Graduate Academic Unit of Electrical and Computer Engineering \\ Supervisor: $\quad$ Prof. Brent R. Petersen, Electrical and Computer Eng. Dept. \\ Examining Board: Prof. Bruce G. Colpitts, Electrical and Computer Eng. Dept., \\ Chair \\ Prof. Christopher P. Diduch, Electrical and Computer Eng. \\ Dept. \\ Prof. Richard J. Tervo, Electrical and Computer Eng. Dept. \\ Prof. John M. DeDourek, Computer Science
}

This thesis is accepted

Dean of Graduate Studies

THE UNIVERSITY OF NEW BRUNSWICK

December, 2008

(C) Karma Kelzang Eudon, 2008 
To My Parents, Gyeltshen and Sonam Chhozom. 


\section{Abstract}

The performance of video streaming over $802.11 \mathrm{~b}$ is evaluated through experimental measurements in the presence of fading due to human traffic, distance and Bluetooth interference, which shares the same 2.4 GHz ISM band.

A measurement network consisting of a desktop connected to the wired internet at the University of New Brunswick (UNB), a wireless laptop and a Bluetooth Smartphone were used for conducting all the measurements which were carried out at UNB within the D level of Head Hall. The received video signal quality was measured in terms of the clock jumps observed in the video showing a ticking analog clock. The results show a Video Capture Range (VCR) for quality video streaming and a Video Lock Range (VLR) where the video signal could not be acquired. The statistical results show significant negative effects of distance and human traffic on video streaming and received video quality. 


\section{Acknowledgements}

I would like to express my profound gratitude to my supervisor, Dr. Brent R. Petersen for his genuine help, invaluable guidance and inspiration. I would also like to deeply thank him for all his generous support and time.

I would like to thank the Canadian International Development Agency (CIDA) for funding my graduate studies, the Royal University of Bhutan as well as the College of Science and Technology for sending me to UNB to pursue my graduate studies.

I would like to acknowledge Mr. Kevin Hanscom for his generous help in my thesis measurements, and for his time and guidance. I would also like to thank the administrative staff of the Electrical and Computer Engineering Department for their support and help.

I would like to thank all my friends for their help, support and motivation. Lastly, I would like to thank God for the blessings, my loving parents, my fiancé, my brother and my sisters for their love, emotional support and encouragement. 


\section{Table of Contents}

Dedication $\quad$ ii

Abstract $\quad$ iii

Acknowledgments $\quad$ iv

Table of Contents $\quad$ v

List of Tables viii

List of Figures $\quad$ ix

Abbreviations $\quad$ xi

1 Introduction 1

1.1 Literature Review . . . . . . . . . . . . . . . . . . . . 1

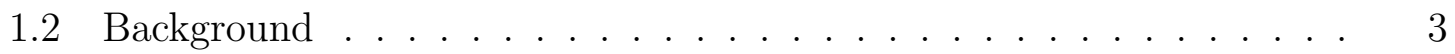

1.2.1 Wireless Standards . . . . . . . . . . . . . . . 3

1.2.1.1 IEEE $802.11 \mathrm{~b} \ldots \ldots \ldots . \ldots \ldots$

1.2.1.2 IEEE 802.15.4/Bluetooth ........... . . 5

1.2.2 Video Streaming . . . . . . . . . . . . . . 5

1.2.3 Radio Wave Propagation . . . . . . . . . . . . . 6

1.2.3.1 Outdoor Environment . . . . . . . . . . 7 
1.2.3.2 Indoor Environment . . . . . . . . . . . 7

1.2.4 Wireless Channel Characteristics ............ 8

1.3 Thesis Contribution . . . . . . . . . . . . . . . . 9

1.4 Thesis Organization . . . . . . . . . . . . . . . . . . . . . 10

2 System Set-up and Implementation $\quad 12$

2.1 Propagation Environment . . . . . . . . . . . . . . . . 12

2.2 Measurement Network . . . . . . . . . . . . . . . . . . . . 14

2.3 Measurement Hardware . . . . . . . . . . . . . . . . . . . . 15

2.4 Data Measurement and Recording . . . . . . . . . . . . . . 17

3 Link Performance of 802.11b 21

3.1 Video Streaming Range . . . . . . . . . . . . . . . . . . . 21

3.1.1 Experimental Set-up . . . . . . . . . . . . . . 21

3.1.2 Data Measurement and Recording . . . . . . . . . . . . . 22

3.1.3 Results and Analysis . . . . . . . . . . . . . . . . 23

3.2 Effect of Distance and Human Traffic . . . . . . . . . . . . . . 25

3.2.1 Experimental Measurement . . . . . . . . . . . . 25

3.2.2 Result and Analysis . . . . . . . . . . . . . . . . 27

3.3 Effect of Bluetooth Interference and Human Traffic . . . . . . . . . . 31

3.3.1 Data Measurement and Recording . . . . . . . . . . . . . 31

3.3.2 Result and Analysis . . . . . . . . . . . . . . . . 33

4 Human Shadowing Effect $\quad 35$

4.1 Impact on Video Streaming and 802.11b Performance . . . . . . . . . 36

4.1.1 Experimental Set-up . . . . . . . . . . . . 36

4.1.2 Data Measurement and Recording . . . . . . . . . . . . . 37

4.1.3 Result and Analysis . . . . . . . . . . . . . . . 39

4.2 Received Signal Power . . . . . . . . . . . . . . . . 46 
4.2.1 Experimental Set-up . . . . . . . . . . . . . . . 47

4.2.2 Data Measurement and Recording . . . . . . . . . . . . . 47

4.2.3 Result and Analysis . . . . . . . . . . . . . . . . . 48

5 Bluetooth Analysis $\quad 51$

5.1 Impact of Bluetooth on Video Streaming and 802.11b Performance . 51

5.1.1 Experimental Set-up and Measurement . . . . . . . . . . . 52

5.1.2 Result and Analysis . . . . . . . . . . . . . . 53

5.2 Impact of Human Traffic on Bluetooth Performance . . . . . . . . . . 55

5.2.1 Experimental Set-up and Measurement . . . . . . . . . . 56

5.2.2 Result and Analysis . . . . . . . . . . . . . . . . 56

6 Conclusion $\quad 60$

6.1 Summary of Work Done . . . . . . . . . . . . . . 60

6.2 Future Work and Recommendations . . . . . . . . . . . . 61

$\begin{array}{ll}\text { Bibliography } & 63\end{array}$

$\begin{array}{lr}\text { Appendices } & 69\end{array}$

$\begin{array}{ll}\text { A Signal Level } & 69\end{array}$

A.1 Signal Level at All Points of Location . . . . . . . . . . . . . . . . . 69

Vita 


\section{List of Tables}

1.1 IEEE Wireless Standards . . . . . . . . . . . . . . . . 4

2.1 Link Performance and Video Quality in Presence of Human Shadowing 18

3.1 Video Streaming Range and Connectivity Status . . . . . . . . . . 24

3.2 Ranges and Locations $\ldots \ldots \ldots \ldots \ldots \ldots$

3.3 Effect of Human Shadowing on the Streamed Video Quality at P9 . . 26

3.4 Distance of Separation Between AP1, MT and BT . . . . . . . . . 32

3.5 Mean Clock Jump at varying BT and MT Separation . . . . . . . 34

4.1 Results of Distance and Human Traffic Effect . . . . . . . . . 40

4.2 Distance from AP1 for Signal Power Measurement . . . . . . . . . 48

5.1 Video streaming in the presence of Bluetooth at P1 in Location 3 . . 54

5.2 Video streaming in the presence of Bluetooth at P2 in Location $3 \ldots 55$

5.3 Human Traffic Effect on Bluetooth System Performance at Q1 . . . 57

5.4 Bluetooth Performance in WLAN Environment in Location $3 \ldots$. . . 58

A.1 Signal Strength Levels at all Locations _ . . . . . . . . . . 70 


\section{List of Figures}

2.1 Overall Floor Plan of all the Locations on D level . . . . . . . . . . 14

2.2 Basic Block Diagram of the Experimental Set-up . . . . . . . . 15

2.3 Measurement Hardware Network . . . . . . . . . . . . . . . . 16

3.1 Floor Plan of Location $3 \ldots \ldots \ldots$

3.2 Human Traffic at Location P9 and P10 . . . . . . . . . . . 28

3.3 Effect of Human Traffic on Live Video Streaming at P9 and P10 . . . 30

3.4 Effect of Human Traffic on Live Video Streaming in Location 3 . . . 30

3.5 Floor Plan of Location $2 \ldots \ldots \ldots$

3.6 Effect of BT-MT Separation on Video Quality . . . . . . . . . . . 33

$4.1 \quad$ Floor Plan of Location $1 \ldots \ldots \ldots$

4.2 Floor Plan of Location $4 \ldots \ldots \ldots$

4.3 Effect of Distance and Human Traffic on Video Streaming Quality in Location $1 \ldots \ldots \ldots \ldots$. . . . . . . . . . . . . . 41

4.4 Effect of Distance and Human Traffic on Video Streaming Quality in Location $3 \ldots \ldots \ldots \ldots$. . . . . . . . . . . . . . . . . 43

4.5 Effect of Distance and Human Traffic on Video Streaming Quality in Location $4 \ldots \ldots \ldots \ldots \ldots$. . . . . . . . . . . . . . 4 44

4.6 Best fit line for the Effect of Distance on Video Streaming Quality in Location 1,3 and $4 \ldots \ldots \ldots \ldots \ldots \ldots \ldots$ 
4.7 Best fit line for the Effect of Human Traffic on Video Streaming Quality

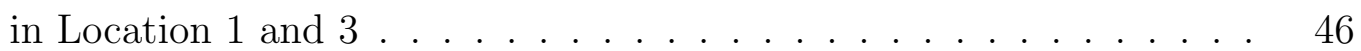

4.8 Average Received Signal Power at Location 1 and 3 . . . . . . . . . . 48

4.9 Human Traffic in Location 1 and 3 respectively for Received Signal Power Measurement . . . . . . . . . . . . . . . . . 50

5.1 BT moving towards AP1 for varying $D_{b t} \ldots \ldots \ldots$. . . . . . . 53

5.2 BT moving away from AP1 for varying $D_{b t} \ldots \ldots \ldots 3$ 


\title{
List of Symbols, Nomenclature or
}

\section{Abbreviations}

\author{
AP1 Access Point 1 \\ AP2 Access Point 2 \\ BT Bluetooth Device \\ $\mathrm{dBm}$ decibels relative to one milliwatt \\ DSSS Direct Sequence Spread Spectrum \\ ECE Electrical and Computer Engineering \\ EMF Electromagnetic Field \\ FCC Federal Communications Commissions \\ FHSS Frequency Hopping Spread Spectrum \\ IEEE Institute of Electrical and Electronics Engineers \\ ISM Industrial, Scientific and Medical \\ ITC Information Technology Centre \\ ITS Integrated Technology Services \\ LOS Line of Sight \\ MT Mobile Transceiver \\ PDA Personal Digital Assistant \\ RF Radio Frequency \\ SAR Specific Absorption Rate
}




$\begin{array}{ll}\text { VCR } & \text { Video Capture Range } \\ \text { VLR } & \text { Video Lock Range } \\ \text { VOD } & \text { Video on Demand } \\ \text { Wi-Fi } & \text { Wireless Fidelity } \\ \text { WCR } & \text { Wi-Fi Capture Range } \\ \text { WLR } & \text { Wi-Fi Lock Range } \\ \text { WLAN } & \text { Wireless Local Area Networking } \\ \text { WPAN } & \text { Wireless Personal Area Networking } \\ \text { m } & \text { Metres } \\ \text { s } & \text { Seconds } \\ \mu \mathrm{s} & \text { Microseconds } \\ \text { W/kg } & \text { Watts per Kilogram } \\ \mathrm{J} / \mathrm{s} / \mathrm{kg} & \text { Joules per Second per Kilogram }\end{array}$




\section{Chapter 1}

\section{Introduction}

Transporting video over the Internet is one of the most popular components of the numerous multimedia applications. In the beginning, the Internet was designed only for data communications and meeting the requirements of video delivery requires significant challenges. The Internet is now available wirelessly and multimedia applications over wireless are possible wherever there is a Wireless Local Area Network (WLAN). One of the most popular standards used for wireless connectivity is IEEE 802.11b. Unfortunately, there are other technologies operating in the same unlicensed band which results in co-channel interference. Apart from the interference due to these technologies, there is also considerable amount of fading in the signal due to obstructions and human shadowing, blocking the signal between the transmitter and receiver.

\subsection{Literature Review}

IEEE 802.11b was introduced in 1999 for wireless connectivity over smaller areas like home, office and some commercial locations. It was around the same time when real-time video streaming came into existence. Since that time, there has been much research done on video streaming. Abukharis et al. [1] described an MPEG2 
video transmission over the IEEE 802.11g in the presence of Bluetooth and measured the quality of the transmitted video signal using the Perceptual Quality Value (PQV) which is defined as an objective measure on the scale of 0 to 100 of the perceptual video quality of an individual video frame.

IEEE 802.11b and Bluetooth are a pair of technologies operating in the same frequency band. Both are proliferating and it is desirable to offer devices which can collocate and simultaneously operate both standards in the same device. There have been many studies done on the impact of Bluetooth on IEEE 802.11b. Linna Hei et al. [2] have simulated a model and evaluated the effect of mutual interference on the performance of Bluetooth and IEEE 802.11b systems when operating in close proximity to each other. Messier et al. [3] and Sarkar et al. [4] have done experimental measurements of Wi-Fi performance in different test environments establishing a relationship between the received power and throughput.

Jo et al. [5] have analyzed and quantified through experimental measurements, influences of environmental mobility, which refers to the ambient motion of people, vehicles or any other objects, on AT\&T WaveLAN, a commercial product designed for constructing 2 Mbps in-building wireless networks. Eckhardt et al. [6] have studied experimentally and reported that "WaveLAN signals are significantly attenuated by a human body and could be more in a crowded lecture room in the building. This attenuation effect would be probably mitigated if a WaveLAN base station were located near the ceiling of that crowded room." The sources of error in the wireless network considered in this study were attenuation, front end overload, narrowband interference and spread spectrum interference.

Villanese et al. [7] show a detailed study of pedestrian-induced fading at three ISM frequencies 2.45, 5.7 and $62 \mathrm{GHz}$ and fading profiles are provided for a point-topoint link in a $150 \mathrm{~m}^{2}$ open-plan office environment. "The fading characteristics are largely independent of frequency and vary with geometry, relative position of transmit 
and receive antennas and the density and pattern of the pedestrian movement" [7]. Varshney et al. [8] have identified and studied the impact of environmental mobility on the wireless channel and they have focused their network study on the specific case of shadowing caused by human beings. They have validated the hypothesis that ambient movement has significant impact on the signal quality through their channel measurement results.

There are many studies showing adverse health effects caused by exposure to electromagnetic fields (EMFs), radio frequency $(\mathrm{RF})$ and microwave radiation. Therefore, countries adhere to limits of exposure of humans to RF signals, governed by the statutes of that particular country. In Canada, these limits are described in Safety Code 6 [9] prepared by the Radiation Protection Bureau of Health Canada which specifies the requirements for the safe use of radiation emitting devices. The basic limits of RF exposure are given in terms of the rate at which RF electromagnetic energy is absorbed in the body which is expressed as specific absorption rate (SAR). "SAR is defined as the rate of RF energy absorption per unit mass in the body and given in units of joules per second per kilogram $(\mathrm{J} / \mathrm{s} / \mathrm{kg})$ or watts per kilogram (W/kg)." Hanna [10] describes a computer program intended to calculate the minimum safe distance from EMFs so as not to exceed the maximum permissible exposure limits of the general public as specified in Safety Code 6 [9].

\subsection{Background}

\subsubsection{Wireless Standards}

Wireless networks were finally introduced into the consumer market through the wireless standard 802.11 ratified in 1997 by the Institute of Electrical and Electronics Engineers (IEEE). This original version of the wireless standard provided data rates of $1 \mathrm{Mbps}$ and $2 \mathrm{Mbps}$. The next wireless standards after the original version 
are listed in Table 1.1.

Table 1.1: IEEE Wireless Standards

\begin{tabular}{|c|c|c|}
\hline \hline Wireless Standard & $\begin{array}{c}\text { Data rate } \\
(\mathrm{Mbps})\end{array}$ & $\begin{array}{c}\text { ISM Band } \\
(\mathrm{GHz})\end{array}$ \\
\hline \hline $802.11 \mathrm{a}$ & 54 & 5 \\
\hline $802.11 \mathrm{~b}$ & 11 & 2.4 \\
\hline $802.11 \mathrm{~g}$ & 54 & 2.4 \\
\hline $802.11 \mathrm{n}$ & 100 & $2.4,5$ \\
\hline
\end{tabular}

These wireless standards soon became popular with the wireless local area network (WLAN), called Wi-Fi. The family of IEEE 802.11 standards supports infrastructure WLANs connection through access points and also allows peer-to-peer communication between terminals [11]. It gained popularity due to several reasons, such as easy setup and management, mobility, cost and portability compared to the wired network.

\subsubsection{IEEE 802.11b}

There are several wireless standards in use but the most popular remains 802.11b which provides higher data rates compared to the original 802.11 standard. 802.11b operates in the 2.4 to $2.4835 \mathrm{GHz}$ ISM band in which it has a channel bandwidth of $22 \mathrm{MHz}$, and therefore has a possibility of three channels in the unlicensed frequency band. It provides a raw data rate up to 11 Mbps with a throughput of about 4 to 5 Mbps. It uses direct sequence spread spectrum (DSSS) technology.

Most of the $802.11 \mathrm{~b}$ implementations include a centralized transceiver which connects or bridges multiple client devices within a particular area of a WLAN. It covers a distance of about $100 \mathrm{~m}$ from the access point which would decrease in case of indoor radio propagation due to the presence of interfering signals or obstructions. Therefore, a full coverage of 802.11 b within the buildings can be assured by calculating the location and right number of base stations or access points. 


\subsubsection{IEEE 802.15.4/Bluetooth}

IEEE 802.15.4 also popularly known as Bluetooth is one form of electronic communication which was introduced to remove the complexity of cables and make wireless personal area networking (WPAN) possible with wireless headsets, wireless peripherals such as keyboards and printers, or wireless synchronization of personal digital assistants (PDAs) with computers [12]. Although, communication without wires has existed for a long time, Bluetooth is focused on smallest localized areas, such as WPAN, and has been widely used for connecting devices wirelessly for computing and telecommunication purposes [13].

Bluetooth employs RF technology in the same 2.4 GHz ISM band as 802.11b and it has a channel bandwidth of 1 MHz. It uses Frequency Hopping Spread Spectrum (FHSS) technology at a rate of 1600 hops/s with a slot period of $625 \mu$ s and hops over $79 \mathrm{MHz}$ of bandwidth [11]. Most of the Bluetooth devices transmit at a power level of about $1 \mathrm{~mW}$ with a raw data rate of $1 \mathrm{Mbps}$. The link range of Bluetooth is normally tens of metres which could be extended to a hundred metres by increasing the transmit power of the Bluetooth device. Although, the maximum transmit power of both IEEE 802.11b and Bluetooth devices are limited to 1 Watt by the Federal Communications Commission (FCC).

The principle of Bluetooth operation at the baseband level consists of two devices forming a piconet where one acts as a master and the others act as slaves. A single master can communicate with a maximum of seven active slaves and up to 255 parked slaves at a time [14].

\subsubsection{Video Streaming}

Video streaming refers to real-time transmission of video which means the audio and video signals must be sent or received continuously. Generally, video can be streamed live or from stored video content known as video on demand (VOD). 
When we say live video streaming, the video content is being played continuously as it is being received and decoded simultaneously. These audio and video signals must be continuously received otherwise they cause irritation to human eyes and ears. Video streaming requires a broadband channel with bandwidth, delay and loss requirements [15].

Streaming live video over a wireless channel causes a great deal of degradation in the video quality due to the fluctuations of wireless channel conditions. Compared to a wired network, it is challenging to obtain quality real-time video over a wireless network. Some of the basic problems are that several wireless technologies share the same channel so the throughput of the wireless channel experiences co-channel interference, multipath fading, i.e. both large-scale fading and small-scale fading, and noise disturbances. Also, the distance between the access point and the mobile points are variable and this causes fluctuations in the capacity of a wireless channel.

Video streaming is quickly gaining popularity. Some of the applications of live video streaming are corporate communications, distance education, web-based channels, interviews and communicating with families and friends in different parts of the world.

\subsubsection{Radio Wave Propagation}

Radio wave propagation is the most essential means of communicating from one location to another wirelessly by transmitting information through electromagnetic waves. The radio waves travel through free space from transmitter to receiver. Generally, radio waves travel through space via several different physical mechanisms such as free-space propagation or LOS propagation, reflection, diffraction, scattering and wave guiding [16]. When the radio waves travel through free space, they dissipate energy which results in attenuation. Free space attenuation is a function of the distance and frequency. Free space attenuation is mainly due to atmospheric absorp- 
tion, hydrometer attenuation, building penetration loss, vegetation attenuation and attenuation due to diffraction [5]. Therefore, the total attenuation in the radio waves is a combination of this free space attenuation and the path loss.

The attenuation of radio wave propagation depends on the radio wave propagation environment. The radio wave propagation environment generally refers to the geographical environment considered for the radio wave propagation between a transmitter and a receiver. Usually, the two environments considered are outdoor and indoor environments.

\subsubsection{Outdoor Environment}

The propagation of radio waves in the outside environment is affected by atmospheric conditions, obstruction of LOS, reflection, refraction and scattering from buildings and other obstacles and human shadowing in the path of propagation [17]. The attenuation caused by obstructions further depends on the material, shape and size of the obstructing object. For example, if the LOS is blocked by a building with walls mostly of reflective glass then we know that the reflection of the radio waves by the glass walls will be more than those of bricks.

\subsubsection{Indoor Environment}

It has generally been stated, [18], [19], [20], [21], [22] and [23] that indoor path loss prediction is more challenging than the outside environment. Indoor radio communication covers a wide range of situations such as moving transceivers within the same building or increasing separation between the receiver and transceiver within the same building. Radio wave propagation is more challenging indoors because the indoor environment consists of a number of obstructions such as partitions, walls, doors, elevators and so on with various kinds of materials. It also includes the position of the access points, the materials of walls, ceilings and floors. The radio waves travel 
through several paths before they reach the receiver and if the separation between the transmitter and receiver is varied then it causes small-scale fading. Even between different floors, there is attenuation of signals which can be quantified by a floor attenuation factor [24] and [25]. Therefore, it is sometimes difficult to have complete coverage of wireless networks indoors but it can be improved by finding out places for more access points within the building.

\subsubsection{Wireless Channel Characteristics}

The wireless channel is different and unpredictable compared to the wireline channel which makes the transmission of quality video over wireless more challenging than the wired network. Some of the factors which contribute to the channel characteristics of a wireless network are multipath and shadow fading, Doppler shift, time dispersion or delay spread. All these factors characterizing the wireless channel results

due to the variability in the environmental conditions introduced by the mobility of the user transmitter or receiver. Fading in the channel is observed to be either fast fading or slow fading. When the signal travels through a large distance between the transmitter and receiver, the signal strength fluctuates around a mean value and it remains for a longer time; this is referred to as 'long-term' or 'slow' fading.

The fading in wave propagation over a wireless channel is mainly characterized by the path loss of the channel, shadowing in the channel and the multipath fading in the channel.

- Path Loss

The signal attenuates as the distance between the transmitter and receiver increases. This path loss is given by,

$$
P_{r}(d)=P_{r}\left(d_{0}\right)\left(\frac{d}{d_{0}}\right)^{n}
$$


where, $P_{r}(d)$ is the path loss at a distance $d, P_{r}\left(d_{0}\right)$ is the path loss at a distance $d_{0}$ and $n$ is the path loss exponent.

As we can see, the signal attenuates exponentially to a constant $n$ whose value depends on the environment. The indoor path loss exponent generally lies between the value 0 to 4 depending on the environmental conditions.

- Shadowing

The signal strength is reduced when it is attenuated due to the presence of buildings, walls, other objects, and humans in the path which blocks the LOS between the transmitter and receiver. The magnitude of this attenuation depends on the type of object between the transmitter and receiver.

- Multipath fading

The signal experiences path loss which results in the weakening of the signal strength. The attenuation of the signal due to the increasing distance between the transmitter and receiver and shadowing by blocking LOS due to objects is called large-scale fading. The attenuation in the signal due to the interference in the signal path due to the varying distance between the transmitter and receiver on the order of the carrier wavelength is called small-scale fading.

\subsection{Thesis Contribution}

The major contributions of this thesis are listed below:

- For video streaming, a VLR and VCR have been observed in measurements and defined.

- This thesis studies the effect of interference of Bluetooth and human shadowing on the quality of video streamed across $802.11 \mathrm{~b}$. 
- The effect of the human traffic, distance and Bluetooth on video streaming over $802.11 \mathrm{~b}$ is measured in a normal daily working environment.

- A statistical analysis of the effect of human traffic, Bluetooth and the combined effect on the quality of video streamed across $802.11 \mathrm{~b}$ is presented.

- This thesis also measures the approximate signal strength required for quality video to be streamed across $802.11 \mathrm{~b}$ in the environment under consideration.

- The common problems are presented with video streaming over $802.11 \mathrm{~b}$ in the presence of human traffic and Bluetooth.

\subsection{Thesis Organization}

Chapter 1 introduces the wireless standards used in this thesis, basic wireless channel characteristics and video streaming.

Chapter 2 describes the experimental set-up used for the measurements in this thesis and the recording of the data collection.

Chapter 3 discusses the study of the link performance of $802.11 \mathrm{~b}$ over the UNB wireless network and studies the effect of human traffic and Bluetooth interference on the link performance. This chapter provides the measurements taken and an analysis of the results obtained.

Chapter 4 provides the measurements taken to study the effect of human shadowing on the quality of video streamed across $802.11 \mathrm{~b}$. This chapter measures an average received signal strength at the mobile transceiver and the analysis of the results is shown.

Chapter 5 contains experimental measurements and analysis of the impact of Bluetooth on the video quality streamed across $802.11 \mathrm{~b}$. This chapter also evaluates the impact of human traffic on Bluetooth performance. 
Chapter 6 includes conclusions, work done for this thesis and recommendations for future work. 


\section{Chapter 2}

\section{System Set-up and Implementation}

\subsection{Propagation Environment}

As discussed in Chapter 1, indoor environment is more challenging than the outdoor environment with the consideration of all kinds of structures within the indoor environment and inconsistent shadowing by human traffic or other interference. These obstructions and the interference in the path of propagation of radio waves is bound to have a degradation effect on the quality of the streamed video across the UNB wireless network. The objective of this thesis is to study the video quality across 802.11b in an indoor environment with normal daily human activity and study the impact of human shadowing and Bluetooth interference. Therefore, the system is set up in a few corridors of the D floor of Head Hall at the UNB Campus.

Currently, Head Hall has a total of seven wireless access points but there are only two on the D level. One of the access points, AP1 is located in the mail room next to the Head Rest and the other, AP2 is ceiling mounted in front of the Integrated Technology Services (ITS) help desk. For this thesis, measurements were taken at four different locations, shown in Figure 2.1, on the D level around the access point, AP1. The four locations are: 
1. Location 1: This location is the corridor along the D level in between the Head Rest and the ITS help desk. This corridor is approximately $20 \mathrm{~m}$ long and has the UNB wireless network through two access points, AP1, which is located in the mail room next to the Head Rest at the front end and AP2, which is located in front of the ITS help desk after a fire door at the other end. Both of these access points are mounted on the ceiling at a height of almost $3.5 \mathrm{~m}$.

2. Location 2: This is the $9.75 \mathrm{~m}$ long and $2.1 \mathrm{~m}$ wide corridor followed by a $12.1 \mathrm{~m}$ long and $3 \mathrm{~m}$ wide glass-walled overpass connecting the Head Rest to the Information Technology Centre (ITC), beside the Electrical and Computer Engineering (ECE) office on the D level in Head Hall. This location could access only AP1.

3. Location 3: This is the $17.4 \mathrm{~m}$ long corridor connecting the Head Rest to the extended old engineering building, opposite H115. This location had to pass through half a flight of stairs and an elevator shift from the access point, AP1. This location could access the UNB wireless network through only AP1 and this was the most interesting location of all, therefore, most of the measurements for Chapter 3 were taken at this location.

4. Location 4: This is the $12.3 \mathrm{~m}$ by $9.45 \mathrm{~m}$ Head Rest which is located right next to the room with the access point, AP1. It is an open area with a $2 \mathrm{~m}$ extended wall on left side of the location and $1 \mathrm{~m}$ extended wall at the right side of the location.

From all the four locations taken for measurements, Location 3 had an interesting combination of the required conditions for measuring the data. At this location, the radio wave propagation path passes along the corridor which acts as a waveguide, but after passing through a turn of a wall and an elevation of $2 \mathrm{~m}$, by a half flight of stairs, from the floor of the Head Rest. Most of the 
measurements were taken along this corridor during the normal working days.

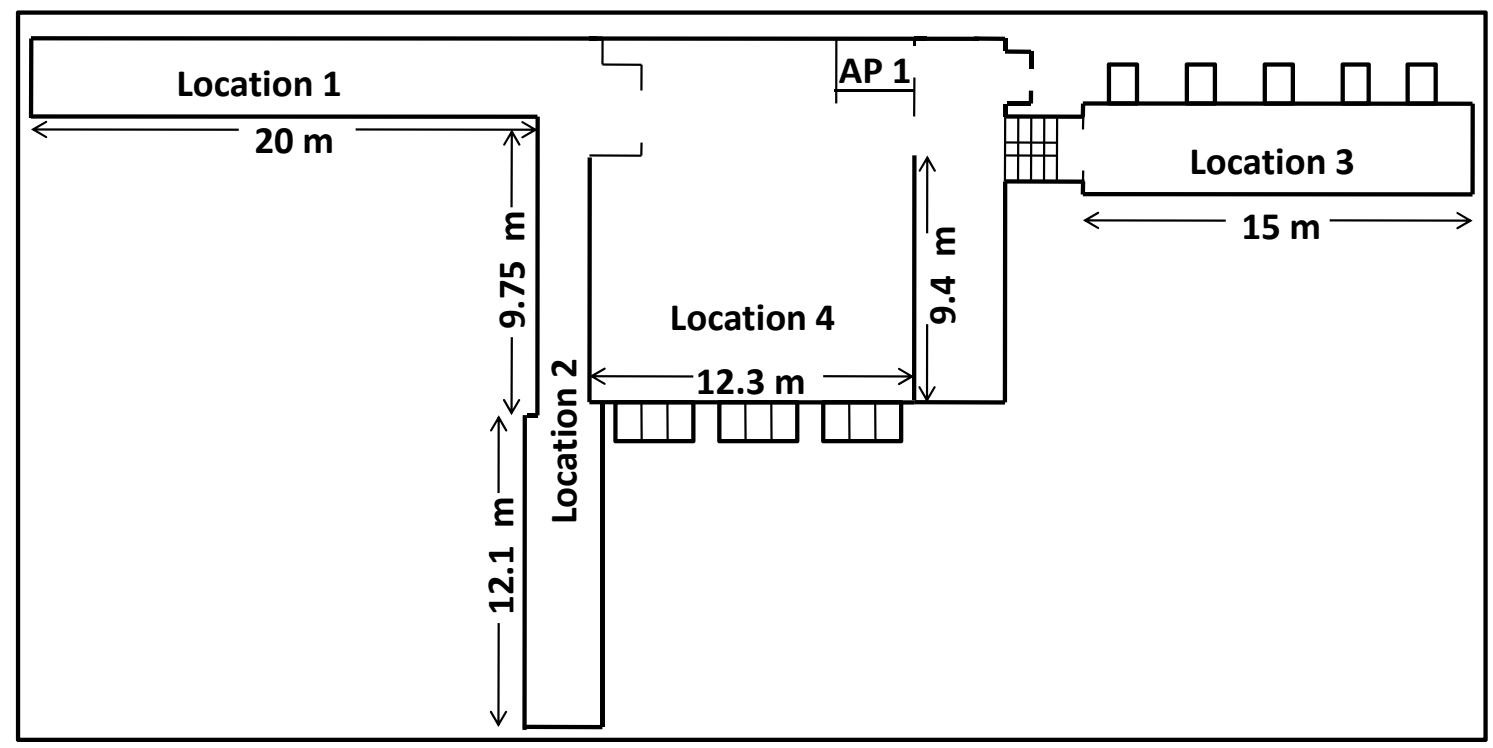

Figure 2.1: Overall Floor Plan of all the Locations on D level

\subsection{Measurement Network}

The goal of this thesis is to measure the quality of live video streamed across the UNB campus wireless network and also study the impact of Bluetooth interference and human traffic on the quality of the video. The block diagram of the basic experimental set-up required for the measurement is shown in Figure 2.2.

As shown in the block diagram, there is raw live video which is captured through a webcam connected to a desktop computer, connected to the wired internet. The mobile station in this case is a Dell laptop which is used as the transceiver. The quality of video in this experiment is measured by placing an analog clock in front of the webcam. The received video from the webcam can be observed on the desktop and this is transmitted via UNB wireless network which uses $802.11 \mathrm{~b} / \mathrm{g}$ wireless technology using one of the most popular instant messaging clients known as Windows Live 


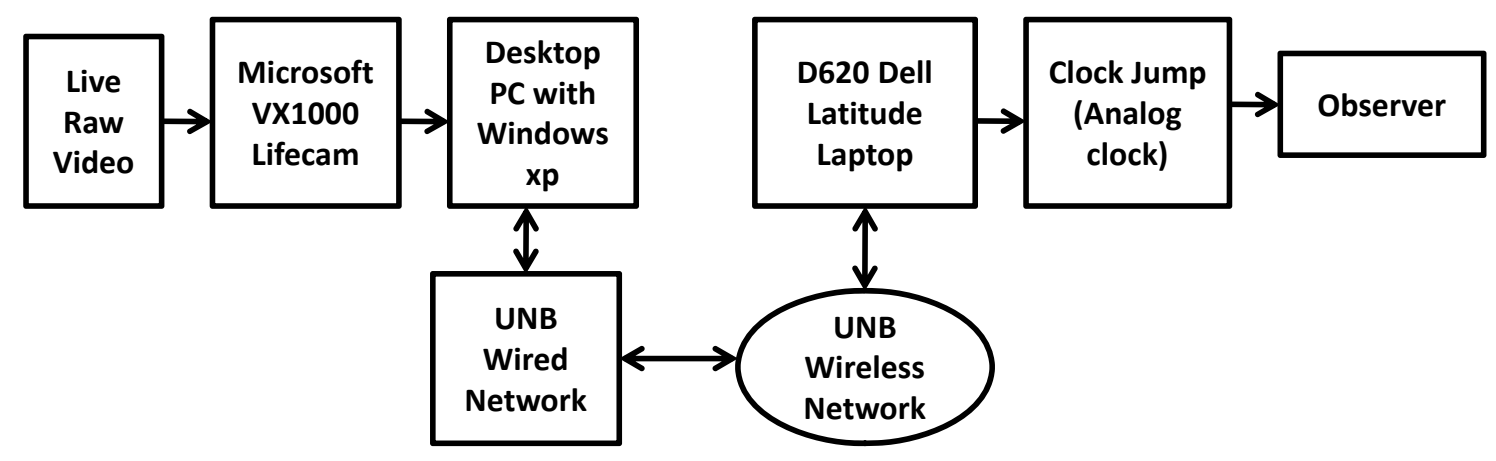

Figure 2.2: Basic Block Diagram of the Experimental Set-up

Messenger, formerly known as MSN Messenger. The transceiver which is a Dell laptop with only an $802.11 \mathrm{~b}$ activated wireless card receives the video via the UNB wireless network and measures the required data. The data is measured mostly by recording the clock jump which means the webcam facing an analog clock sends a video of this clock ticking normally. When the video received on the other end shows that the clock has stopped ticking, the time is recorded, and also, when the clock starts to tick again. The difference between the two times recorded gives the clock jump which may have been caused due to Bluetooth interference, human traffic or low link quality due to distance. The data is measured according to the requirement for the analysis to be done as shown in later chapters of this thesis.

\subsection{Measurement Hardware}

One of the WLANs used for streaming video across $802.11 \mathrm{~b}$ has the access point located in the mail room next to the Head Rest of Head Hall on the D level. The access point is positioned at the ceiling next to the wall facing the Head Rest at a height of approximately $3.5 \mathrm{~m}$. The mobile transceiver (MT) is an Intel ${ }^{\circledR}$ Centrino ${ }^{\circledR}$ Duo, 1.66 GHz, 1 GB RAM, Microsoft ${ }^{\circledR}$ Windows $^{\circledR}$ xp Professional Version 2002, D620 Dell Latitute laptop with an Intel ${ }^{\circledR} \mathrm{PRO} /$ Wireless $3945 \mathrm{Wi}-\mathrm{Fi} 802.11 \mathrm{~b} / \mathrm{g}$ connection card 
but for this thesis, only $802.11 \mathrm{~b}$ is activated. To study the effect of Bluetooth interference on the quality of streamed video across $802.11 \mathrm{~b}$, a piconet between the MT and a Bluetooth device (BT) is formed using a Palm Treo 700wx Smartphone. The video is sent using a Microsoft ${ }^{\circledR}$ LifeCam VX-1000 webcam mounted on a desktop with an Intel ${ }^{\circledR}$ Pentium $^{\circledR} 4$ CPU $1.70 \mathrm{GHz}, 768 \mathrm{MB}$ RAM, and Microsoft ${ }^{\circledR}$ Windows $^{\circledR}$ xp Professional Version 2002. Figure 2.3 shows a simple measurement network set-up at all locations for measuring data.

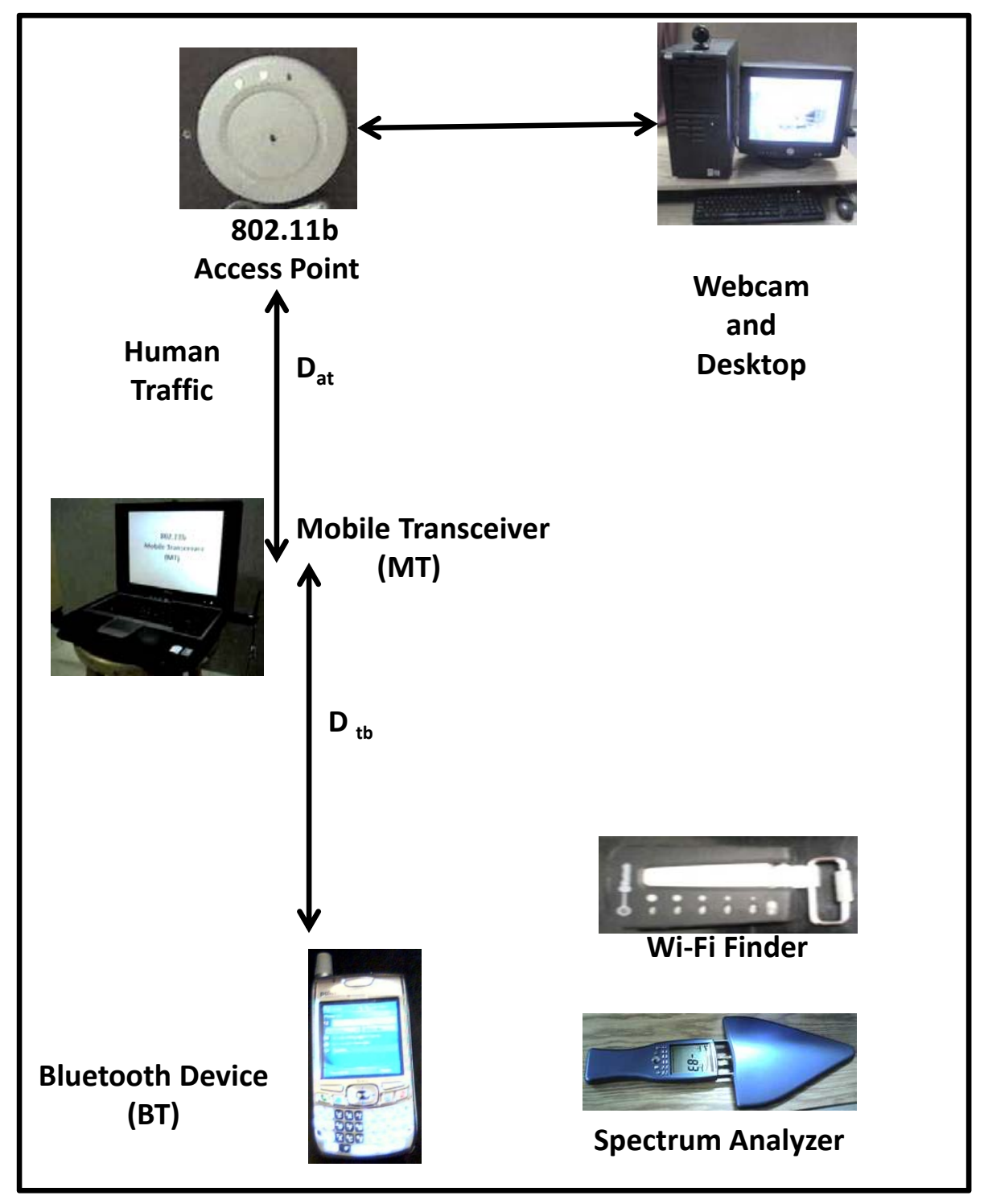

Figure 2.3: Measurement Hardware Network 
As seen in Figure 2.3, the distance between the access point and the MT is given as $D_{\text {at }}$ and this distance can be varied by moving the MT closer to or farther away from the access point. Similarly, the separation between the MT and BT is given as $D_{\text {tb }}$ which is also varied by moving the BT with every new location of the MT. This variation in the separation between the access point and the mobile transceiver, as

well as that of the mobile transceiver and the Bluetooth device, is necessary to study how the quality of video streamed across $802.11 \mathrm{~b}$ is affected with these variations of distance of separation.

An HF SPECTRAN spectrum analyzer is used to measure the average signal strength and power level of the receiver station and a $150 \mathrm{~m}$ measuring tape is used to measure the distances. The power level at the MT is measured in $\mathrm{dBm}$ which gives us the average signal strength received at the MT during live video streaming. A Kensington Wi-Fi finder was used to easily locate areas with Wi-Fi coverage.

\subsection{Data Measurement and Recording}

The data were measured in an environment with normal human activity in order to study the link performance of $802.11 \mathrm{~b}$ during video streaming in a normal day-to-day environment. The measurements were done with different situations as explained below:

1. First, the quality of video was measured without any Bluetooth interference or human traffic between the access point and the mobile station. The distance between the access point and the MT was increased and data were recorded for studying the link performance of $802.11 \mathrm{~b}$ with increasing distance.

2. After measuring the link performance without any interference, the link performance was measured by observing the video quality streamed across $802.11 \mathrm{~b}$ in the presence of human traffic and Bluetooth, respectively. In both the cases, 
Table 2.1: Link Performance and Video Quality in Presence of Human Shadowing

\begin{tabular}{|c|c|c|c|c|c|c|c|}
\hline $\begin{array}{c}S \\
(60 \mathrm{~s}) \\
\end{array}$ & $\begin{array}{l}\text { Blue- } \\
\text { tooth }\end{array}$ & $\begin{array}{c}\text { Arrival } \\
\text { time of } \\
\text { the human } \\
\tau_{a} \\
(\mathrm{~s})\end{array}$ & $\begin{array}{c}\text { Human } \\
\text { Traffic } \\
h_{1} \\
\text { (people) }\end{array}$ & $\begin{array}{c}\text { Jump } \\
\text { start } \\
\text { time } \\
\tau_{j 1} \\
(\mathrm{~s}) \\
\end{array}$ & $\begin{array}{c}\text { Jump } \\
\text { stop } \\
\text { time } \\
\tau_{j 2} \\
(\mathrm{~s}) \\
\end{array}$ & $\begin{array}{l}\text { Clock } \\
\text { jump } \\
\tau_{j 3} \\
(\mathrm{~s}) \\
\end{array}$ & Comment \\
\hline 1 & Off & 0 & 0 & 17 & 20 & 3 & No effect \\
\hline 1 & Off & 35 & 1 & 0 & 0 & 0 & No effect \\
\hline 2 & Off & 15 & 1 & 0 & 15 & 15 & Affected \\
\hline 2 & Off & 44 & 1 & 44 & 45 & 1 & Affected \\
\hline 3 & On & 0 & 0 & 45 & 47 & 2 & No effect \\
\hline 3 & On & 0 & 0 & 17 & 22 & 5 & No effect \\
\hline 4 & On & 25 & 1 & 25 & 40 & 15 & Affected \\
\hline
\end{tabular}

the measurements were done by varying the distance between the access point and the mobile station. For the latter case, the distance between the BT and the MT was also varied to study the effect of Bluetooth interference strength with distance on the streamed video.

3. The quality of streamed video across $802.11 \mathrm{~b}$ was then measured in the presence of both Bluetooth interference and human traffic. Along with the introduction of Bluetooth interference and human shadowing, the distance between the access point and the MT was changed.

All these measurement scenarios were considered in a natural human traffic environment whereas the Bluetooth interference was introduced as and when required for the measurement purposes. The data measured is recorded as required for achieving the objectives of this thesis. The data were later recorded in Excel as shown in Table 2.1 and recorded data were used for studying link performance and video quality.

The Excel sheet for this data includes the measurement of the video quality streamed across $802.11 \mathrm{~b}$ so as to study its link performance with and without interference and human shadowing. The data measured and recorded in Table 2.1 is explained as follows: 


\section{Column 1 : Sets}

This column represents sets of sixty seconds during which the measurements are taken and the unit is seconds. It is represented by the symbol $\mathrm{S}$ and it gives the total number of sets of sixty seconds taken for measuring the data to study the effect of human traffic and Bluetooth interference on the quality of streamed video across $802.11 b$.

\section{Column 2: Bluetooth}

The data measurement is done in the normal daily environment but this thesis aims to study the impact of Bluetooth on the streamed video quality which is not present, therefore, Bluetooth interference has been introduced for the measurement. This column shows whether the Bluetooth device is 'On' or 'Off' during the measurement.

3. Column 3 : Arrival time of the human

In the sets of sixty seconds during the data measurement, the time during which a person walks or people walk by the corridor is recorded in this column. It is represented by the symbol $\tau_{a}$ and its unit is seconds. It keeps track of human traffic along the measuring environment.

4. Column 4 : Human traffic

This column is represented by $h_{1}$ which gives the number of people walking along the measuring environment.

\section{Column 5 : Jump start time}

The quality of video streamed across $802.11 \mathrm{~b}$ is measured in terms of clock jumps by observing the ticking of the clock. This column is represented by $\tau_{j 1}$ in seconds which records the time in the sixty second set in which the clock stops 
ticking due to: the network quality at that location, Bluetooth interference, human shadowing or all combined together.

6. Column 6 : Jump stop time

This column which is represented by $\tau_{j 2}$, in seconds, records the time at which the clock starts ticking again due to: the network quality improvement, the removal of Bluetooth interference, or absence of human traffic.

7. Column 7 : Clock jump

The difference between data recorded in column 5 and column 6 gives the clock jump at that point in that time, i.e. $\tau_{j 3}=\tau_{j 2-} \tau_{j 1}$, in seconds. The clock had a second hand which moved in discrete $1 \mathrm{~s}$ steps. When the clock was observed to tick normally, in discrete $1 \mathrm{~s}$ steps, then it was recorded as a $0 \mathrm{~s}$ clock jump, where the video quality obtained was perfect. When the clock showed lazy ticking, where one observed that a $1 \mathrm{~s}$ tick took longer than $1 \mathrm{~s}$, i.e. approximately $1.5 \mathrm{~s}$, then the clock jump was recorded as a $1 \mathrm{~s}$ clock jump.

\section{Column 8: Comment}

This last column in the table shows whether the streamed video was affected or not during that environmental condition at that time in that particular location.

The measurement of fading due to human traffic was measured in terms of streamed video quality across $802.11 \mathrm{~b}$, with and without Bluetooth interference. The distance between the access point and the MT was changed to study the effect with increasing distance. When the test was performed with Bluetooth interference, the distance between the master and slave was also changed to study its effect on the streamed video quality as well as Bluetooth performance. The detailed result and analysis of the recorded data are shown in the later chapters of this thesis. 


\section{Chapter 3}

\section{Link Performance of $802.11 b$}

This chapter uses the system set-up described in Chapter 2 and is used to statistically analyze the link performance of $802.11 \mathrm{~b}$ with the measured data. This chapter studies the effect of human traffic on the link performance of $802.11 \mathrm{~b}$ via the UNB wireless network. The human shadowing effect on the quality of streamed video is studied with real-time measurements and results are discussed.

\subsection{Video Streaming Range}

\subsubsection{Experimental Set-up}

The measurement network was set up to study the link performance of $802.11 \mathrm{~b}$ in Location 3, described in Chapter 2. The experimental lay-out is shown in Figure 3.1. Location 3 is a $3 \mathrm{~m}$ wide and $17.4 \mathrm{~m}$ long corridor near AP1 through a narrow $2 \mathrm{~m}$, half flight of stairs, which is located in between the Head Rest and the old engineering building in Head Hall.

The measurement environment has access to only one access point, AP1 and besides having weak radio signal coverage, the hallway acts as a waveguide for the radio signal, which proves to be advantageous for the experimental measurements. It 


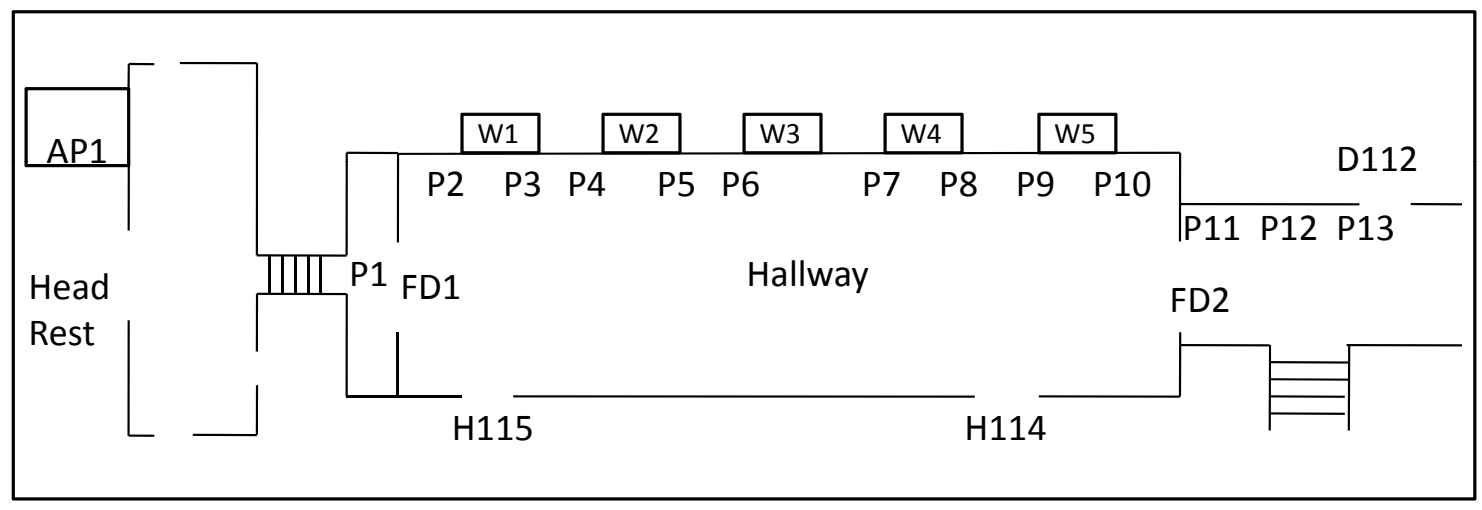

Figure 3.1: Floor Plan of Location 3

is also observed that this location has five $1 \mathrm{~m}$ by $2 \mathrm{~m}$ windows, W1, W2, W3, W4 and W5, and two exit points at the two ends through fire doors, FD1 and FD2. The fire door at P1, FD1 was kept open throughout the experiment and the fire door at the other end was kept open for measurements at locations P11, P12 and P13.

There are two machines in this experiment where one of the machines is a desktop with Windows ${ }^{\circledR}$ xp having Windows Live Messenger, version 8.5 installed in it and is connected to the wired internet of UNB. The other machine is a laptop which is identified as MT. The measurements were taken during a normal day-to-day working environment so as to achieve the objectives of this thesis in a natural working environment.

\subsubsection{Data Measurement and Recording}

The data were measured in Location 3 during a normal working day of the university. The measurement network was set up at increasing distances from AP1 at various points identified as P1, P2, ... , P12, as shown in Figure 3.1. The MT was first placed at P1 and recorded the measured data, then the distance between the MT and AP1 was increased and data were recorded at increasing distances until the point P13 where the MT could not access the UNB wireless network. 
For Location 3, the measurement environment had weak signal strength where there was an interesting observation at the MT. It was observed that there were certain points in the measurement environment with varying ranges of live video streaming and connectivity to the Wi-Fi. These ranges which were observed in the measurement environment without any human traffic or Bluetooth interference are explained as follows:

1. Wi-Fi Lock Range (WLR): This range is identified as a location in the measurement environment in which the MT cannot get connected to the UNB wireless network.

2. Wi-Fi Capture Range (WCR): This range is identified as a point in the measurement environment where the MT is able to connect to the UNB wireless network and is able to remain connected but is not able to stream live video.

3. Video Lock Range (VLR): This range is identified as a point in the measurement environment where the MT is not able to stream live video after reconnecting to Wi-Fi at this point but is able to maintain the streaming of live video continued from a previous point.

4. Video Capture Range (VCR): This range is identified as a point in the measurement environment where the MT is able to establish and maintain a connection to Wi-Fi, thereby making continuous live video streaming possible.

The measurement was done at various increasing distances from AP1 and the data were recorded as shown in Table 3.1 to identify the four ranges for Location 3.

\subsubsection{Results and Analysis}

Location 3 had weak signal coverage which led to the existence of all the above four ranges for the possibility of continuous live video streaming. The radio signal 
Table 3.1: Video Streaming Range and Connectivity Status

\begin{tabular}{|c|c|c|c|c|c|}
\hline Locations & $\begin{array}{c}\text { Distance } \\
\text { from AP1 } \\
\text { (m) }\end{array}$ & $\begin{array}{c}\text { Able to } \\
\text { connect } \\
\text { to Wi-Fi }\end{array}$ & $\begin{array}{c}\text { Wi-Fi } \\
\text { connection } \\
\text { status }\end{array}$ & $\begin{array}{c}\text { Able to } \\
\text { stream } \\
\text { live video }\end{array}$ & $\begin{array}{c}\text { Live video } \\
\text { streaming } \\
\text { status }\end{array}$ \\
\hline \hline P1 & 8 & Yes & Connected & Yes & Streaming \\
\hline P2 & 9.1 & Yes & Connected & Yes & Streaming \\
\hline P3 & 10.3 & Yes & Connected & Yes & Streaming \\
\hline P4 & 12.2 & Yes & Connected & Yes & Streaming \\
\hline P5 & 13.7 & Yes & Connected & Yes & Streaming \\
\hline P6 & 15.5 & Yes & Connected & Yes & Streaming \\
\hline P7 & 19 & Yes & Connected & Yes & Streaming \\
\hline P8 & 20.1 & Yes & Connected & Yes & Streaming \\
\hline P9 & 21.9 & Yes & Connected & Yes & Disconnected \\
\hline P10 & 23.2 & Yes & Connected & Yes & Disconnected \\
\hline P11 & 26.5 & Yes & Connected & No & No connection \\
\hline P12 & 27.7 & Yes & Disconnected & No & No connection \\
\hline P13 & 32.0 & No & No connection & No & No connection \\
\hline
\end{tabular}

Table 3.2: Ranges and Locations

\begin{tabular}{|c|c|c|}
\hline Ranges & Location & $\begin{array}{c}\text { Distance from AP1 } \\
(\mathrm{m})\end{array}$ \\
\hline VCR & P9 & 21.9 \\
\hline VLR & P11 & 26.5 \\
\hline WCR & P12 & 27.7 \\
\hline WLR & P13 & 32 \\
\hline
\end{tabular}

weakened further as the MT moved away from AP1. The ranges for Location 3 were observed at points as given in Table 3.2.

From Table 3.2, we can observe that the VCR is found to be at a distance of $21.9 \mathrm{~m}$ from AP1 and the video streaming is observed to be smoother and without any discontinuity whereas if the MT is moved at a distance of $26.5 \mathrm{~m}$ away from AP1 then the video streaming is observed to be discontinuous. At the VLR, the MT is able to reconnect to the Wi-Fi but is not able to reconnect to Windows Live Messenger for live video streaming but the interesting observation was that if the video had been 
streaming which was connected from a previous point (closer to AP1) then it could maintain the continuity of video streaming up to this point. Similarly, the MT could reconnect to the $\mathrm{Wi}-\mathrm{Fi}$ up to a distance of $27.7 \mathrm{~m}$ from AP1 but beyond that, it could only remain connected to the Wi-Fi up to a distance of $32 \mathrm{~m}$ from AP1 if it was previously connected at a location less than $27.7 \mathrm{~m}$. Thus, it is observed clearly from Table 3.1 that the four ranges exist in the sequence: $V C R \rightarrow V L R \rightarrow W C R \rightarrow W L R$ in increasing order of the distance from the access point.

\subsection{Effect of Distance and Human Traffic}

\subsubsection{Experimental Measurement}

The experiment was conducted in the same environment i.e. Location 3 as shown in Figure 3.1. The measurement was done in the presence of human traffic so as to study the effect of human traffic at various points defined in Figure 3.1 in terms of the effect of human traffic on the quality of streamed video with increasing distance from the access point. The measurements were taken at all positions in Location 3 and there was an interesting observation at Locations P9 and P10 in the presence of human traffic. The measured data for one of these particular locations i.e. P9 is shown in Table 3.3 .

Table 3.3 has seven columns which are defined as follows:

1. Column 1: Sets $(S)$ represents the time period in sets of sixty seconds.

2. Column 2: Time, $\tau_{a}$ gives the arrival time within the set of sixty seconds at which a person walks or people walk into the measurement environment.

3. Column 3: It is represented by $h_{1}$, which gives the number of people in the measuring environment. 
Table 3.3: Effect of Human Shadowing on the Streamed Video Quality at P9

\begin{tabular}{|c|c|c|c|c|c|c|}
\hline $\begin{array}{c}S \\
(60 \mathrm{~s})\end{array}$ & $\begin{array}{c}\text { Arrival } \\
\text { time of the } \\
\text { human traffic } \\
\tau_{a} \\
(\mathrm{~s})\end{array}$ & $\begin{array}{c}\text { Human } \\
\text { traffic } \\
\\
h_{1} \\
\text { (people) }\end{array}$ & $\begin{array}{c}\text { Jump } \\
\text { start } \\
\text { time } \\
\tau_{j 1} \\
(\mathrm{~s})\end{array}$ & $\begin{array}{l}\text { Jump } \\
\text { stop } \\
\text { time } \\
\tau_{j 2} \\
(\mathrm{~s})\end{array}$ & $\begin{array}{l}\text { Clock } \\
\text { jump } \\
\\
\tau_{j 3} \\
(\mathrm{~s})\end{array}$ & Comment \\
\hline 1 & 0 & 0 & 49 & 51 & 2 & No effect \\
\hline 2 & 0 & 0 & 52 & 54 & 2 & No effect \\
\hline 3 & 0 & 0 & 40 & 42 & 2 & No effect \\
\hline \multirow[t]{2}{*}{4} & 0 & 0 & 23 & 30 & 7 & No effect \\
\hline & 0 & 0 & 41 & 43 & 2 & No effect \\
\hline \multirow[t]{2}{*}{5} & 2 & 1 & 2 & 15 & 13 & Affected \\
\hline & 2 & 0 & 17 & 15 & 2 & Affected \\
\hline 6 & 0 & 0 & 8 & 10 & 12 & No effect \\
\hline \multirow[t]{2}{*}{7} & 2 & 1 & 2 & 19 & 17 & Affected \\
\hline & 40 & 2 & 0 & 0 & 0 & No effect \\
\hline 8 & 5 & 1 & 5 & 25 & 2 & Affected \\
\hline \multirow[t]{2}{*}{9} & 0 & 1 & 10 & 12 & 20 & No effect \\
\hline & 0 & 0 & 49 & 51 & 2 & No effect \\
\hline 10 & 0 & 0 & 16 & 18 & 2 & No effect \\
\hline \multirow[t]{2}{*}{11} & 0 & 0 & 13 & 15 & 2 & No effect \\
\hline & 0 & 0 & 41 & 50 & 9 & No effect \\
\hline 12 & 0 & 0 & 50 & 52 & 2 & No effect \\
\hline \multirow[t]{5}{*}{13} & 0 & 0 & 0 & 2 & 2 & No effect \\
\hline & 0 & 0 & 17 & 19 & 2 & No effect \\
\hline & 0 & 0 & 23 & 24 & 1 & No effect \\
\hline & 0 & 0 & 43 & 45 & 2 & No effect \\
\hline & 51 & 2 & 51 & 64 & 13 & Affected \\
\hline \multirow[t]{2}{*}{14} & 0 & 0 & 28 & 30 & 2 & No effect \\
\hline & 0 & 0 & 50 & 52 & 2 & No effect \\
\hline \multirow[t]{2}{*}{15} & 0 & 0 & 17 & 19 & 2 & No effect \\
\hline & 0 & 0 & 28 & 30 & 2 & No effect \\
\hline
\end{tabular}


4. Column 4: Jump-start time, $\tau_{j 1}$, in seconds, records the time at which the clock stops ticking during the measurement.

5. Column 5: Jump stop time, $\tau_{j 2}$, in seconds, records the time when the clock starts to tick again during the measurement.

6. Column 6: Clock jump, $\tau_{j 3}$ is given by the difference between the jump stop time and jump start time i.e. $\tau_{j 3}=\tau_{j 2-} \tau_{j 1}$.

From Table 3.3, we can understand that the network is unstable during continuous clock jumps. Besides the Wi-Fi condition at that particular time and location, there are clock jumps at P9 and P10 in Location 3 as shown in Figure 3.2 in the presence of human traffic. This shows that there is clock jump due to the human body shadowing in the path of the radio signal propagation at this location.

\subsubsection{Result and Analysis}

The data collected for locations P9 and P10 with the human traffic as shown in Figure 3.2 is used to analyse the distance and human shadowing effect on the video quality. In the figure, the clock jumps are shown within a set of sixty seconds, S1, $\mathrm{S} 2, \ldots . . \mathrm{S} 15$, i.e. $\mathrm{S} 1$ represents a time interval of 1-60 s, S2 represents 61-120 s, and so on. As we have discussed earlier, P9 is one of the points where the video quality is affected by human shadowing. We can clearly observe from Figure 3.2 that the signal strength is weak as there is a clock jump throughout the video streaming even when there is no human traffic. Similarly, in Figure 3.2, we can observe that the signal strength is much weaker at P10 and more unstable as it has higher clock jumps compared to P9. P10 has more continuous jumps, i.e. more than one jump in a sixty second set, e.g. the set S6 representing the time interval 301-360 s for Location P10 with no human traffic has four clock jumps of 12 s, 2 s, 12 s and another $12 \mathrm{~s}$. The mean and median clock jumps observed were $4.4 \mathrm{~s}$ and $2 \mathrm{~s}$ at 

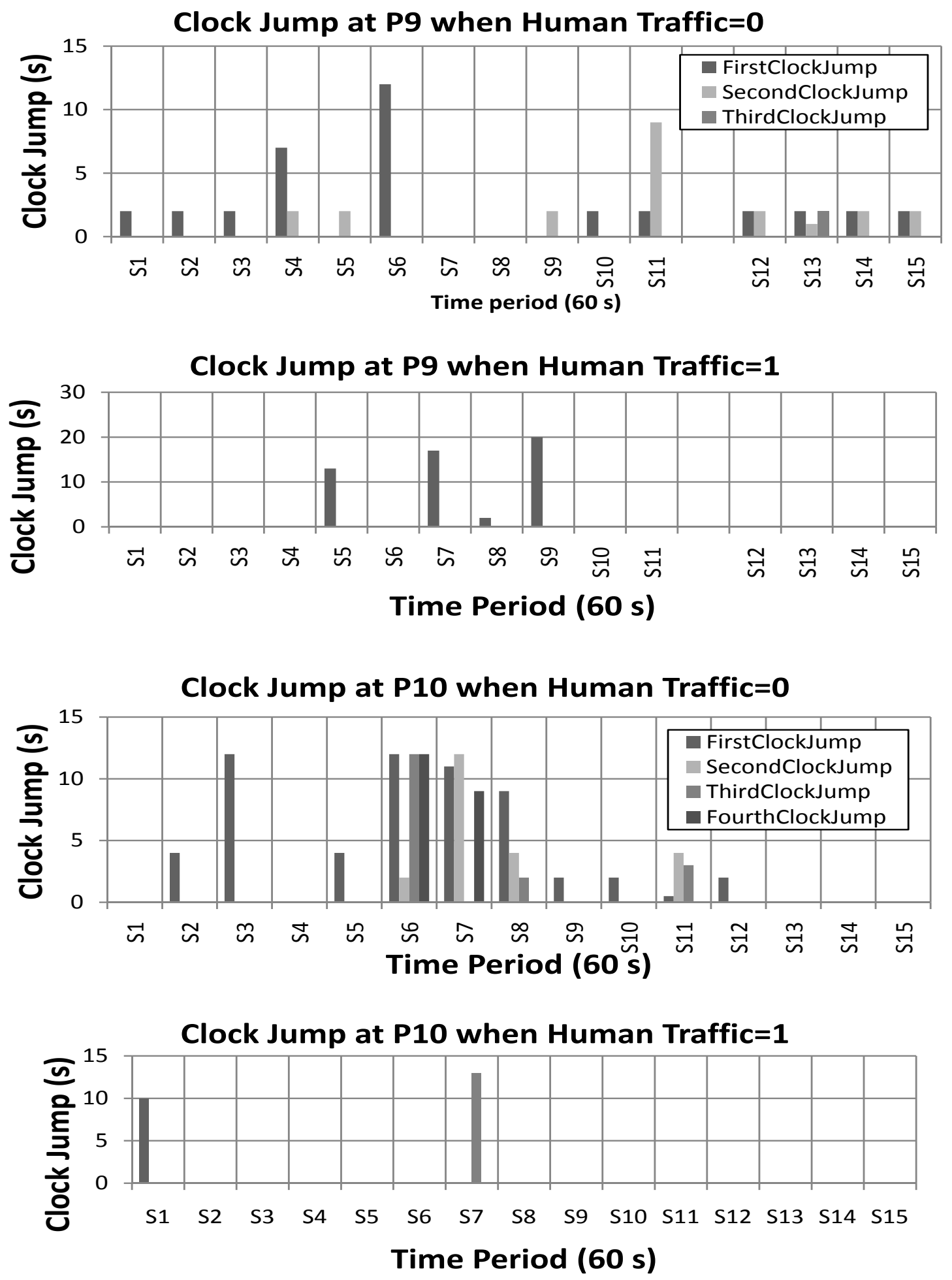

Figure 3.2: Human Traffic at Location P9 and P10 
P9 and $5.9 \mathrm{~s}$ and $4 \mathrm{~s}$ at P10, respectively. Although, there were more clock jumps at P10 compared to P9, P9 had higher standard deviation than P10 by a value of 0.6. Unfortunately, the measurements were taken during the summer term and the human traffic was mostly one person. But there was an interesting observation at this particular location at one time, i.e. when two people started walking towards the laptop and they stopped at around $3 \mathrm{~m}$ distance, the MT lost the Wi-Fi connection due to human body shadowing. Villanese et al. [7] have examined pedestrian-induced fading characteristics at 2.45, 5.7 and $62 \mathrm{GHz}$ by considering the effects of wave obstruction by the human body but this is beyond the scope of this thesis.

From Figure 3.3, we can get a clearer observation that the average clock jump at P10 is higher than P9 by $1.5 \mathrm{~s}$. The medians at P9 and P10 are $2 \mathrm{~s}$ and $4 \mathrm{~s}$, respectively, which indicates that the average duration of clock jump is more at P10. This shows that P10, being $1.3 \mathrm{~m}$ further away than P9, had weaker signal coverage. Every time a person walks into the measurement environment, there is degradation in the quality of the streamed video, which demonstrates the presence of human shadowing. Similarly, the overall result for the other points in Location 3, i.e. P2, P3, P4, P5, P6, P7 and P8 is shown in Figure 3.4 where we can clearly observe that the average clock jump increases as the MT moves further away from AP1 with a slight deflection at $\mathrm{P} 4$ where a frequent number of clock jumps were observed even with no human traffic.

These experimental results show that there is a degradation in the quality of streamed video with increasing distance and presence of human traffic in the environment. Thus, it agrees with Varshney et al. [8] who have concluded in their paper that people cause shadowing of the wireless signal leading to poor received quality. 


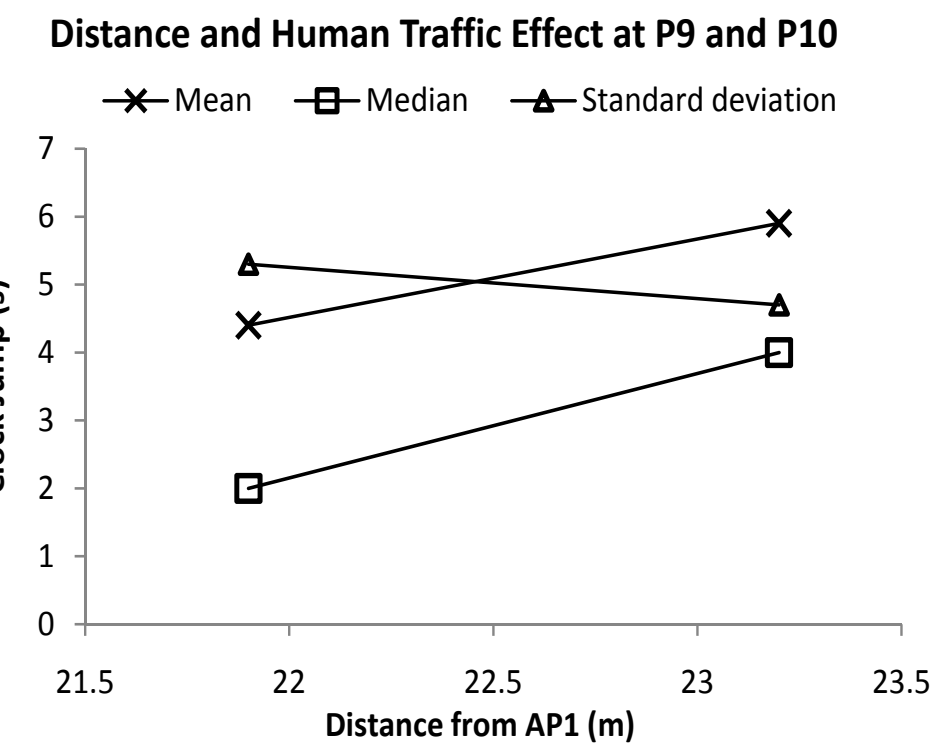

Figure 3.3: Effect of Human Traffic on Live Video Streaming at P9 and P10

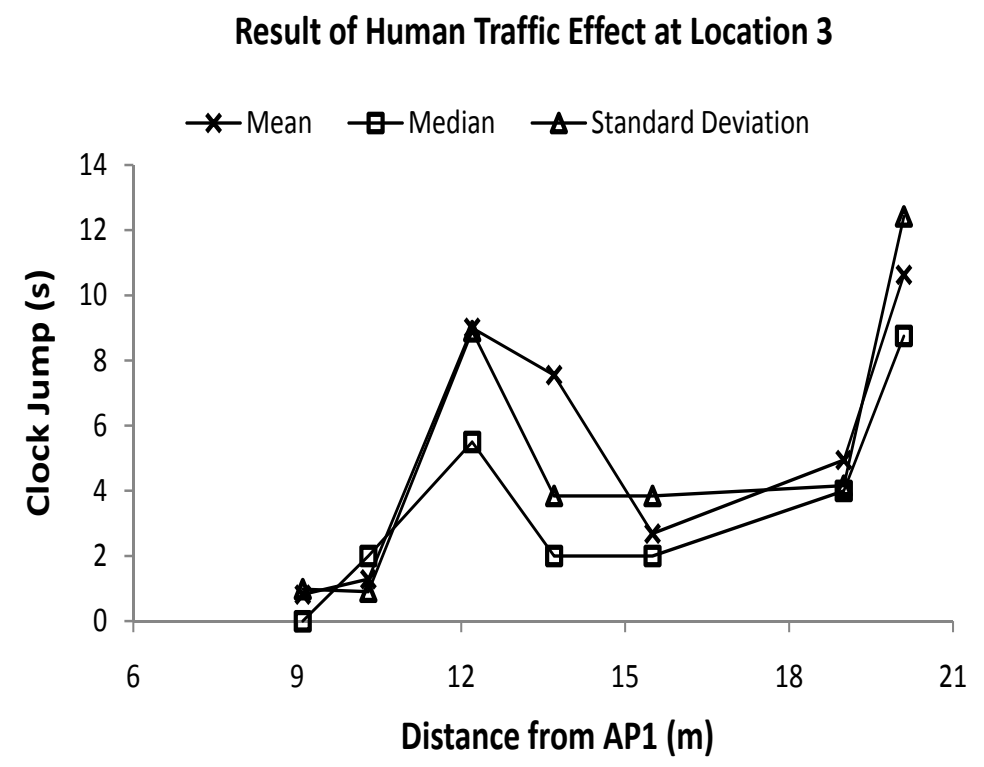

Figure 3.4: Effect of Human Traffic on Live Video Streaming in Location 3 


\subsection{Effect of Bluetooth Interference and Human Traffic}

The measurement network was set up in Location 3 for studying the effect of Bluetooth interference and human traffic but every time the Bluetooth connection was set-up between the BT and the MT, the Wi-Fi connection was lost. Thus the measurement network was set-up in Location 2 which is a a $9.75 \mathrm{~m}$ long and $2.1 \mathrm{~m}$ wide corridor next to the ECE office in the D level of the Head Hall. This corridor is connected to another $12 \mathrm{~m}$ long and $3 \mathrm{~m}$ wide corridor through a fire door which connects to the next building, Information Technology Centre (ITC). The layout of Location 2 is shown in Figure 3.5.

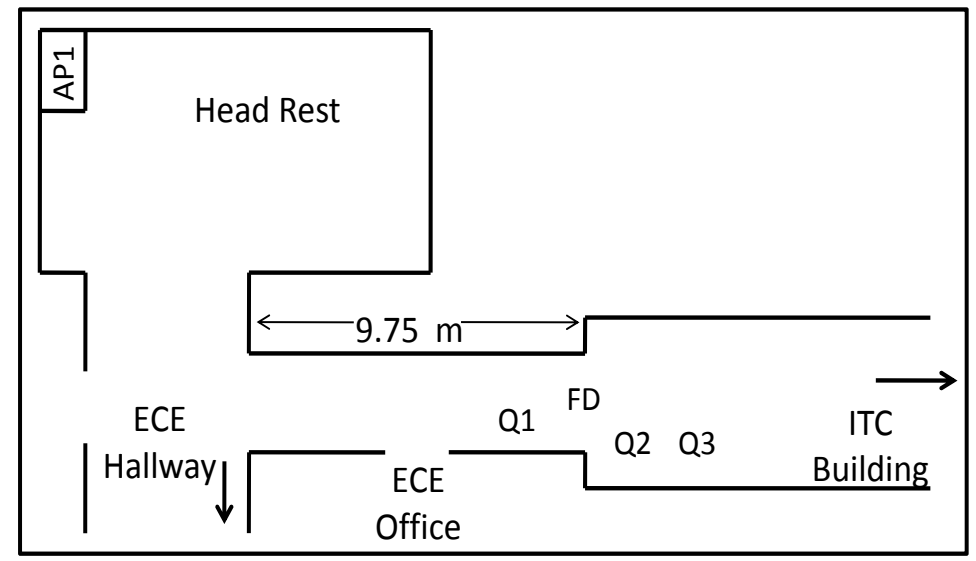

Figure 3.5: Floor Plan of Location 2

\subsubsection{Data Measurement and Recording}

The data measurements were taken at Location 2 during normal working days. The measurements were taken as per the requirement to fulfill the objectives of this thesis. The measurement network as explained in Chapter 2 was taken in the measurement environment and then the BT was placed in between AP1 and the MT. 
Table 3.4: Distance of Separation Between AP1, MT and BT

\begin{tabular}{|c|c|c|c|}
\hline $\begin{array}{c}\text { Position } \\
\text { of MT in } \\
\text { Location 2 }\end{array}$ & $\begin{array}{c}\text { Distance } \\
\text { between } \\
\text { AP1 and MT } \\
D_{a t} \\
(\mathrm{~m})\end{array}$ & $\begin{array}{c}\text { Distance } \\
\text { between } \\
\text { AP1 and BT } \\
D_{a b} \\
(\mathrm{~m})\end{array}$ & $\begin{array}{c}\text { Distance } \\
\text { Between } \\
\text { BT and MT } \\
D_{t b} \\
(\mathrm{~m})\end{array}$ \\
\hline \hline Q1 & 20 & 19.7 & 0.3 \\
\hline Q1 & 20 & 19.1 & 0.9 \\
\hline Q1 & 20 & 18.5 & 1.5 \\
\hline Q1 & 20 & 17.9 & 2.1 \\
\hline Q1 & 20 & 20.9 & 0.9 \\
\hline Q2 & 24.4 & 25.9 & 1.5 \\
\hline Q2 & 24.4 & 26.5 & 2.1 \\
\hline
\end{tabular}

The BT was switched on and connected to the MT in the presence of human traffic during the measurement. The BT was then switched off and the separation between the MT and the BT, $D_{t b}$ was varied for the measurement.

The measurement points at Location 2 were identified as Q1 and Q2 as it was difficult to define the ranges at this particular location because there was no difference in the video quality observed at Q1 and any points closer than Q1 whereas the MT was unable to connect to Wi-Fi at any point after Q2. It was quite difficult collecting data at Q2 because the MT often lost the Wi-Fi connection and had to come back to location Q1 to reconnect. The data were measured at varying separations between the BT and MT, as shown in Table 3.4.

As shown in Table 3.4, the MT was positioned at a fixed distance of $20 \mathrm{~m}$ from AP1 and the separation between the BT and the MT was varied in both the directions, i.e. closer and farther from AP1. At each separation, the data were measured to study the effect of Bluetooth interference along with human traffic on the quality of streamed video. 


\subsubsection{Result and Analysis}

The data were collected with varying separations between the BT and the MT at both the points, Q1 and Q2 in Location 2. Since Q2 was located in the next corridor through the fire door and also having glass walls, the MT could not stay connected to the Wi-Fi. Therefore, the data was measured mostly at location Q1 where it was observed to have a lesser effect on the quality of video due to human traffic but was highly affected by the Bluetooth interference. BT was placed at six distances of separation with the MT, moving towards and away from AP1 as shown earlier in Table 3.4 .

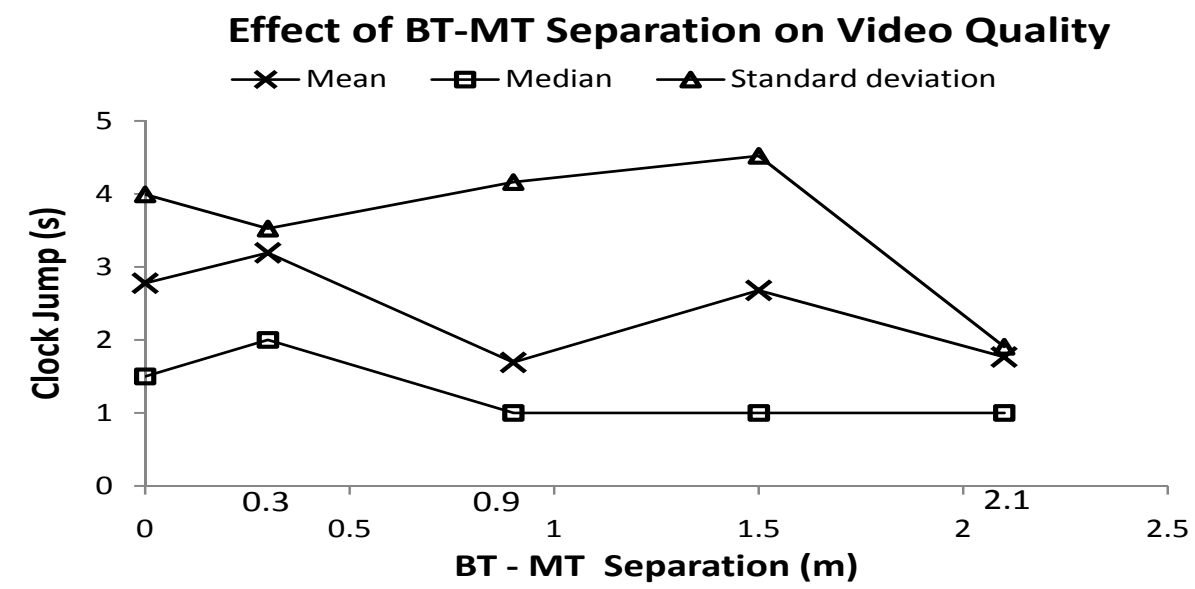

Figure 3.6: Effect of BT-MT Separation on Video Quality

When the BT is switched on, there are many clock jumps during a 60 s set. At a separation of $0.3 \mathrm{~m}$ from the MT, the BT seems to highly influence the quality of video with more clock jumps, with a mean clock jump of $3.2 \mathrm{~s}$. When the distance of separation was increased to $0.9 \mathrm{~m}$, there were still many clock jumps of $1 \mathrm{~s}$ throughout with an exception of a large clock jump of $20 \mathrm{~s}$. At a separation of $1.5 \mathrm{~m}$, there is a slightly higher clock jump than $1 \mathrm{~s}$ at few points bringing the mean clock jump to $2.6 \mathrm{~s}$. As the separation is increased further to $2.1 \mathrm{~m}$, the clock jump reduces with a mean clock jump of $1.7 \mathrm{~s}$. All the mean values of the clock jumps at all distances of 
Table 3.5: Mean Clock Jump at varying BT and MT Separation

\begin{tabular}{|c|c|c|}
\hline $\begin{array}{c}\text { Distance between } \\
\text { MT and BT } \\
D_{t b} \\
(\mathrm{~m})\end{array}$ & $\begin{array}{c}\text { Distance between } \\
\text { BT and AP1 } \\
D_{a b} \\
(\mathrm{~m})\end{array}$ & $\begin{array}{c}\text { Mean Clock Jump } \\
\qquad \tau_{m} \\
(\mathrm{~s})\end{array}$ \\
\hline 0.3 & 19.7 & 3.2 \\
\hline 0.9 & 19.1 & 1.7 \\
\hline 1.5 & 18.5 & 2.6 \\
\hline 2.1 & 17.9 & 1.7 \\
\hline 0.3 & 20.3 & 2.8 \\
\hline 0.9 & 20.9 & 1.3 \\
\hline
\end{tabular}

separation for this measurement are shown in Table 3.5.

In Figure 3.6, we can obseve that the median clock jump at all BT-MT separations remains almost consistent at $1 \mathrm{~s}$ in this location. Although, the average clock jump seems to slightly reduce with the increase in separation between the BT and the MT, except for at $1.5 \mathrm{~m}$ separation which resulted due to a $20 \mathrm{~s}$ clock jump at $221 \mathrm{~s}$ during the $300 \mathrm{~s}$ measurement time for that particular separation.

There is a clear comparison between the quality of the received video in the presence and absence of Bluetooth interference as well as at various separations of the BT from the MT. Although, the quality of video seems to be less affected by human traffic at this location since the signal strength is stronger being closer to AP1. The results show that the closer the BT is placed to the MT, the higher the clock jump, showing degradation in the quality of the streamed video, which is in agreement with the experimental results of Keller et al. [26], which show a significant degradation in the performance of both the systems (Bluetooth and WLAN). 


\section{Chapter 4}

\section{Human Shadowing Effect}

There is an increasing demand for quality multimedia streaming and one of the technical problems to be investigated for this purpose is to determine the effect of fading on network performance. This chapter evaluates the effect of human shadowing and distance of the radio signal propagation which affects the quality of streamed video over $802.11 \mathrm{~b}$. This chapter describes measurements of the received signal strength during video streaming over $802.11 \mathrm{~b}$ in the presence of human traffic.

Human shadowing is generally understood as the blockage of the radio propagation path for wireless communication. Obayashi et al. [27] have described that the propagation loss by body shadowing affects the received signal strength and Villanese

et al. [7] have concluded that human shadowing is mainly caused by rays reflecting off a biological body, thus the combined effect of human traffic with a moving receiver can strongly impair the quality of wireless communication system. 


\subsection{Impact on Video Streaming and 802.11b Per- formance}

We understand that video streaming over a wireless network is more challenging than a wired network due to the variablility in environmental conditions affecting the wireless channel characteristics. Generally, these variations introduce more noise and interference in the wireless channels compared to the wired channel. Increases in noise and interference cause increases in the bit error rate, and this high error rate can cause a degradation in the video quality. Therefore, it is necessary to have robust transmission of video over wireless channels. In this chapter, we measure the impact of fading in the quality of streamed video over $802.11 \mathrm{~b}$ in the presence of fading due to human traffic in different locations at varying distances from the access point.

\subsubsection{Experimental Set-up}

The measurement network described in Chapter 2 was used for measuring data in all the four locations mentioned in Chapter 2. The overall layout of the four locations in the D level of Head Hall is shown in Figure 2.1 in Chapter 2. The measurements were taken in these four locations which had, at the time of measurement, varying environmental conditions as described below:

- Location 1: This hallway being in the same floor as that of the access point is the main corridor of the ECE Department and seemed busier compared to the other locations. The floor plan of this location is shown in Figure 4.1. When the measurement was taken at the other end away from the Head Rest, closer to AP2, the signal from access point AP2 could be accessed along with AP1. This location had a classroom, a few offices and a workshop occupied by people using the network as well as one using Bluetooth during the time of measurement. 
- Location 2: The first corridor of this location is in between the ECE office and the Head Rest where there are a couple of network users and a Bluetooth user during the time of measurement.

- Location 3: This location is the hallway in the old engineering building, elevated $2 \mathrm{~m}$, half flight of stairs, above the floor of the Head Rest. Therefore, the signal strength is weakest at this location compared to the other three locations which gave most of the interesting data. There were no other Bluetooth users during the time of measurement.

- Location 4: This location is the Head Rest which is located right next to an access point and has a strong signal strength. There were fewer people using the wireless network but no Bluetooth user at the time of measurement.

All the measurements were taken during a normal working environment at all four locations in Head Hall.

\subsubsection{Data Measurement and Recording}

The measurements were taken in all the four locations during normal working days. The same measurements were first taken in Location 3 followed by Location 4 , Location 2 and Location 1 . The measured data for all the locations were recorded and details of measurement procedures for all the four locations are given below:

- Location 1: The layout of Location 1 is given in Figure 4.1. The measurements were taken at six different points R1, R2, R3, R4, R5 and R6 in this $20 \mathrm{~m}$ long corridor as shown in Figure 4.1 and all these measurements were taken during normal working days.

- Location 2: The layout is given in Figure 3.5 in Chapter 3. The measurements were taken in three different locations Q1, Q2 and Q3 in the two corridors at 


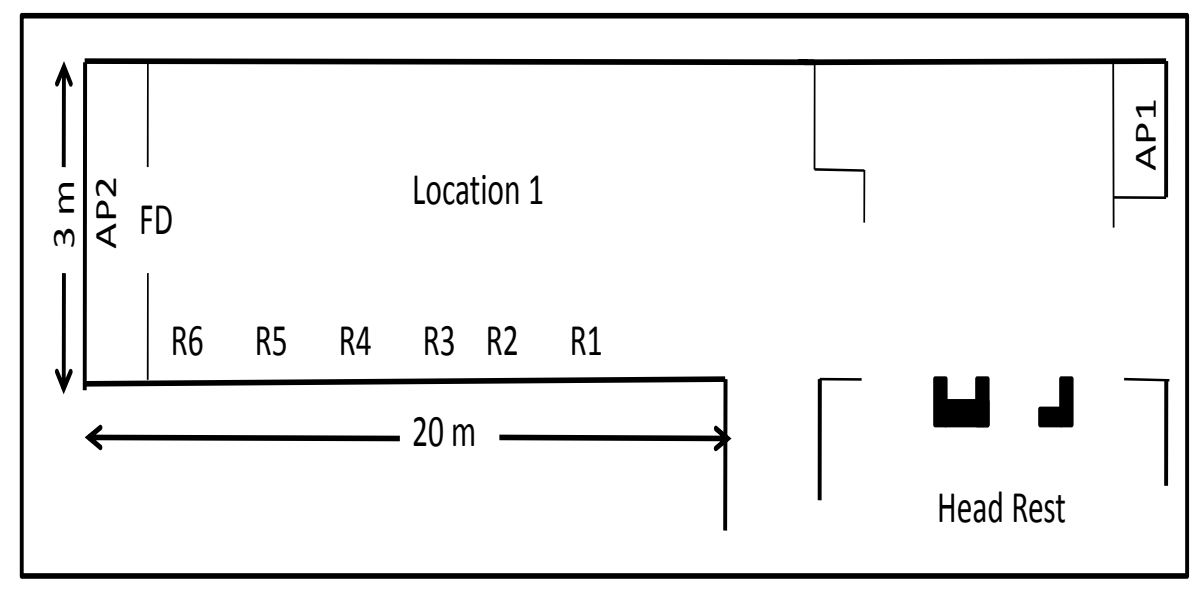

Figure 4.1: Floor Plan of Location 1

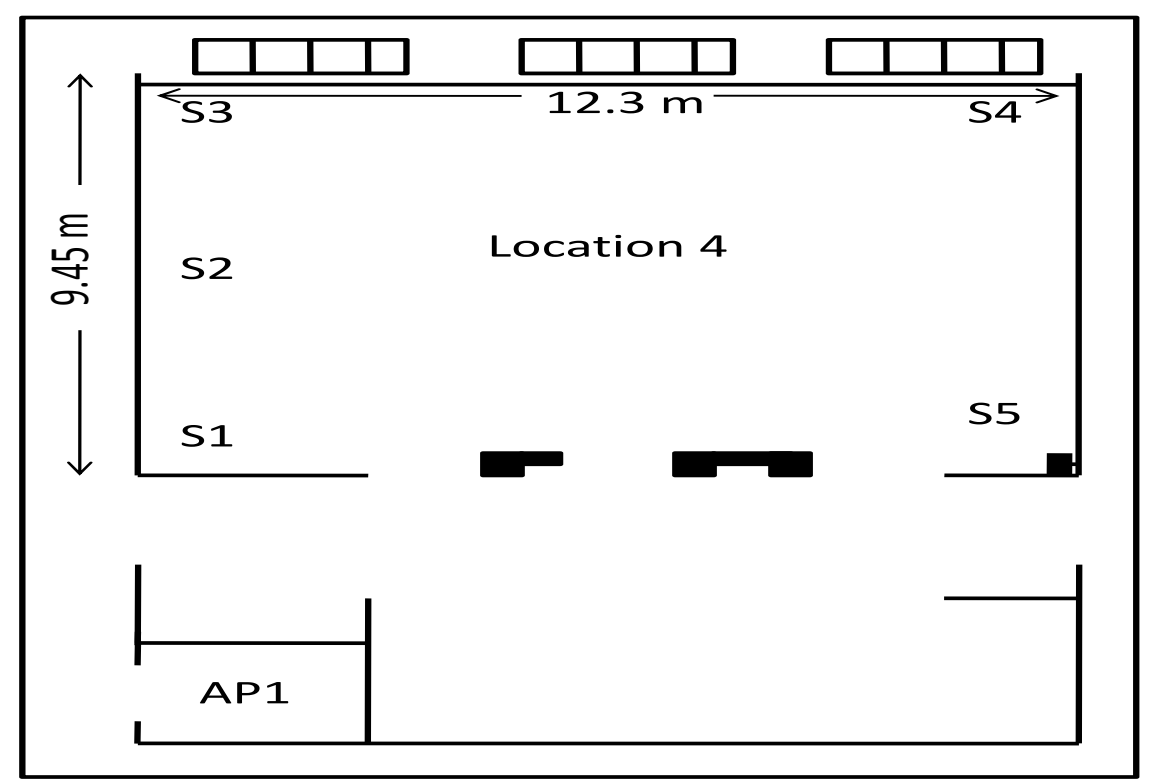

Figure 4.2: Floor Plan of Location 4 
Location 2. There was one interesting observation at point Q2 during a very humid day after a light shower of rain. There was great difficulty in getting connected to the Wi-Fi on this particular day at this location and even if the connection was established, it would disconnect after every 3 to 5 minutes. The condition was worse when the Bluetooth device was switched on and therefore, the same measurement had to be repeated on other days. The MT when placed at Q3 could not at all get connected to the Wi-Fi. Therefore, the distance effect on video quality could not be evaluated in this location.

- Location 3: The layout is given in Figure 3.1 in Chapter 3 and all the same points were taken for this measurement. This location was less busy as compared to all the other three locations.

- Location 4: The layout is given in Figure 4.2 and the measurements were taken at six different points $\mathrm{S} 1, \mathrm{~S} 2, \mathrm{~S} 3, \mathrm{~S} 4, \mathrm{~S} 5$ and $\mathrm{S} 6$ in this location.

\subsubsection{Result and Analysis}

The results of the data measured at all the three locations are summarized in Table 4.1 and discussed below:

- Location 1:

As the MT was set-up and trying to access Wi-Fi, it took a couple of minutes and change in location to get stably connected to the network. The data collected shows that there are more clock jumps as the MT moves further away from the access point. The mean clock jump in this location is seen to increase with the increase in distance, as shown in Figure 4.3 except at R1 where there was a clock jump of $6 \mathrm{~s}$ at the $14^{\text {th }} \mathrm{s}$ when 6 people walked into the measurement environment. We observe that R5 has the highest average clock jump of $3 \mathrm{~s}$ in this location because it was at this location when there were 8 people in the 
Table 4.1: Results of Distance and Human Traffic Effect

\begin{tabular}{|c|c|c|c|c|}
\hline Location & $\begin{array}{c}\text { Distance } \\
(\mathrm{m})\end{array}$ & $\begin{array}{c}\text { Mean Clock Jump } \\
(\mathrm{s})\end{array}$ & $\begin{array}{c}\text { Median } \\
(\mathrm{s})\end{array}$ & Standard Deviation \\
\hline \hline R1 & 13.4 & 1.5 & 0.5 & 2.5 \\
\hline R2 & 15.2 & 1.4 & 1 & 0.5 \\
\hline R3 & 19 & 0.8 & 0.5 & 1.1 \\
\hline R4 & 22.5 & 1 & 1 & 1.1 \\
\hline R5 & 27.4 & 3 & 1 & 3.2 \\
\hline R6 & 29.2 & 2.6 & 1.5 & 3.4 \\
\hline P2 & 9.1 & 0.8 & 0 & 1 \\
\hline P3 & 10.3 & 1.2 & 2 & 0.9 \\
\hline P4 & 12.2 & 9 & 5.5 & 8.8 \\
\hline P5 & 13.7 & 7.55 & 2 & 14 \\
\hline P6 & 15.5 & 4.5 & 2 & 11.1 \\
\hline P9 & 21.9 & 8.5 & 2 & 7.5 \\
\hline S1 & 3.3 & 4.7 & 2 & 7.9 \\
\hline S2 & 6.1 & 4.5 & 0 & 1.7 \\
\hline S3 & 8.8 & 3 & 0 & 2.5 \\
\hline S4 & 14.6 & 1.3 & 1 & \\
\hline S5 & 18.3 & 1.2 & 0 & \\
\hline
\end{tabular}

hallway for $152 \mathrm{~s}$ during the time of measurement. The number of clock jumps observed were more at R2 compared to R3, thereby, giving a higher mean at R2 whereas R3 had higher variation of clock jumps. It is observed that the standard deviation increases with the increase in distance with the highest, at point R6, of 3.4 which shows that there is higher variation in clock jumps at the MT as it moves further away from AP1 affecting the quality of live video streaming.

- Location 3:

As seen from Figure 4.4 and Table 4.1, there was human traffic during the time of measurement at points P2, P3, P4 and P5 but unfortunately, there was no human traffic at P6 and P9. Therefore, the results show a higher mean of clock jumps at P4 and P5 of values $9 \mathrm{~s}$ and 7.5 s respectively. Also, the median clock jump at P4 is the highest with a value of $5.5 \mathrm{~s}$ because there was a person 


\section{Effect of Distance on Video Streaming at Location 1}

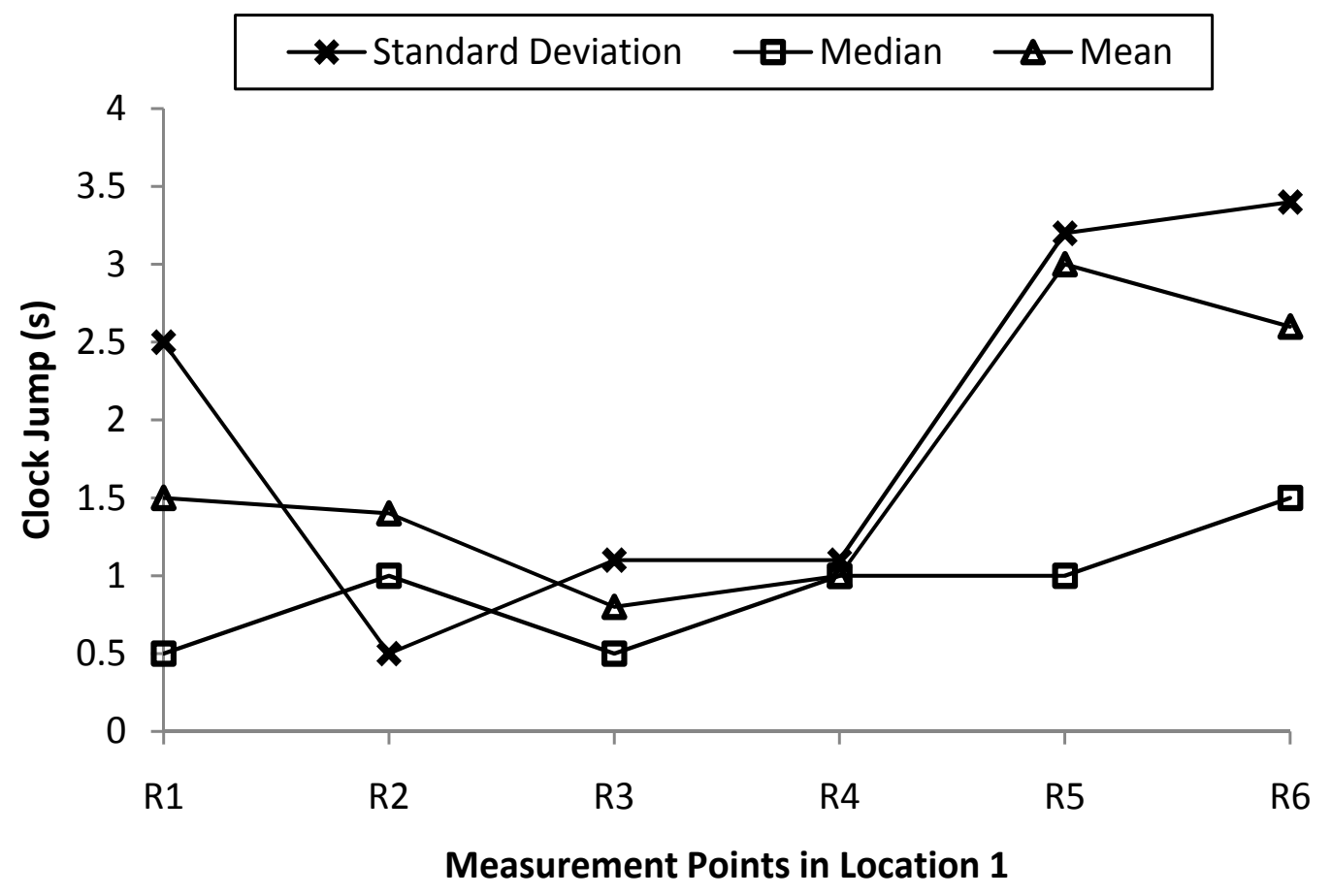

Human Traffic in Location 1

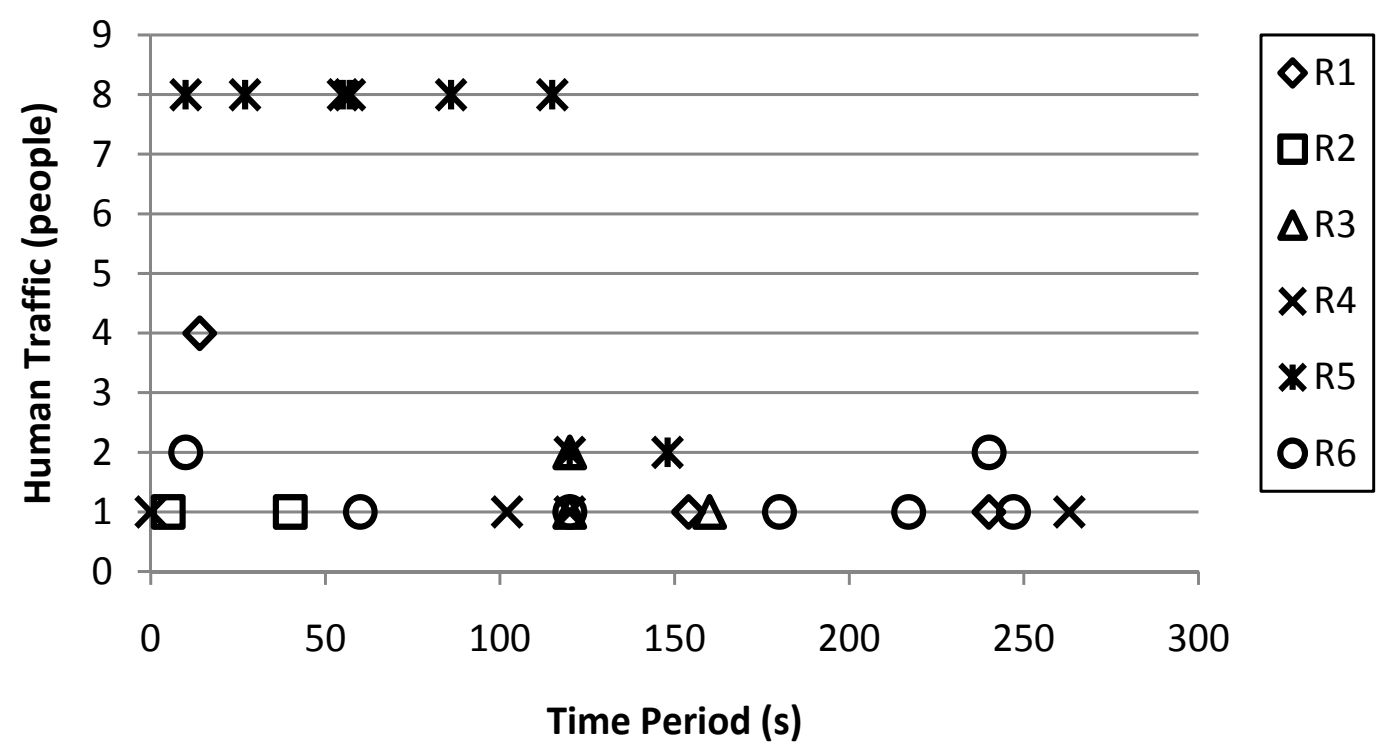

Figure 4.3: Effect of Distance and Human Traffic on Video Streaming Quality in Location 1 
walking through the hallway at the 239th, 274th and 299th s during the time of measurement. Although, P4 had the largest clock jump, it is observed that P5 has more variation in the clock jump. Figure 4.4 shows that the effect of distance and human traffic on the video quality is more as the MT moves further away from AP1.

- Location 4: This location being the Head Rest, located right next to the room with the access point, had people walking in the measurement environment during most of the time. In this environment, there were two large vending machines right next to the wall opposite to the Head Rest. As can be seen from the layout of this location in Figure 4.2, points S1, S2 and S3 were behind the wall of the Head Rest and S4 and S5 were in the open area. This explains the large variation in the clock jumps in this location where the average clock jump in the first three points of measurement varied from 3 to $4.75 \mathrm{~s}$ and 1.2 to $1.3 \mathrm{~s}$ for the last two points. The results also show that there were higher variations of clock jumps in the first three points in the presence of human traffic which can be understood more clearly from the graph shown in Figure 4.5.

Therefore, the evaluations are summarized by obtaining the best fit line for the data collected at all the three locations as shown in Figure 4.6. From Figure 4.6, we can clearly observe that the slopes of best fit lines in Location 1 and 3 are positive which shows a positive linear relationship between the average clock jumps at all points of measurement and the distance of these points from the access point. Thus, the larger the clock jumps observed, the more is the degradation in the video quality. For Location 4, we can observe that the slope of the best fit line is negative which may be due to moving toward a reflected path. Pahlavan et al. [28] have described that metallic objects such as relatively large electric motors, equipments and vending machines increases the harshness of the indoor environment for radio propagation. As a result, the average clock jumps decreases as we move further away from the access 


\section{Effect of Distance on Video Streaming at Location 3}

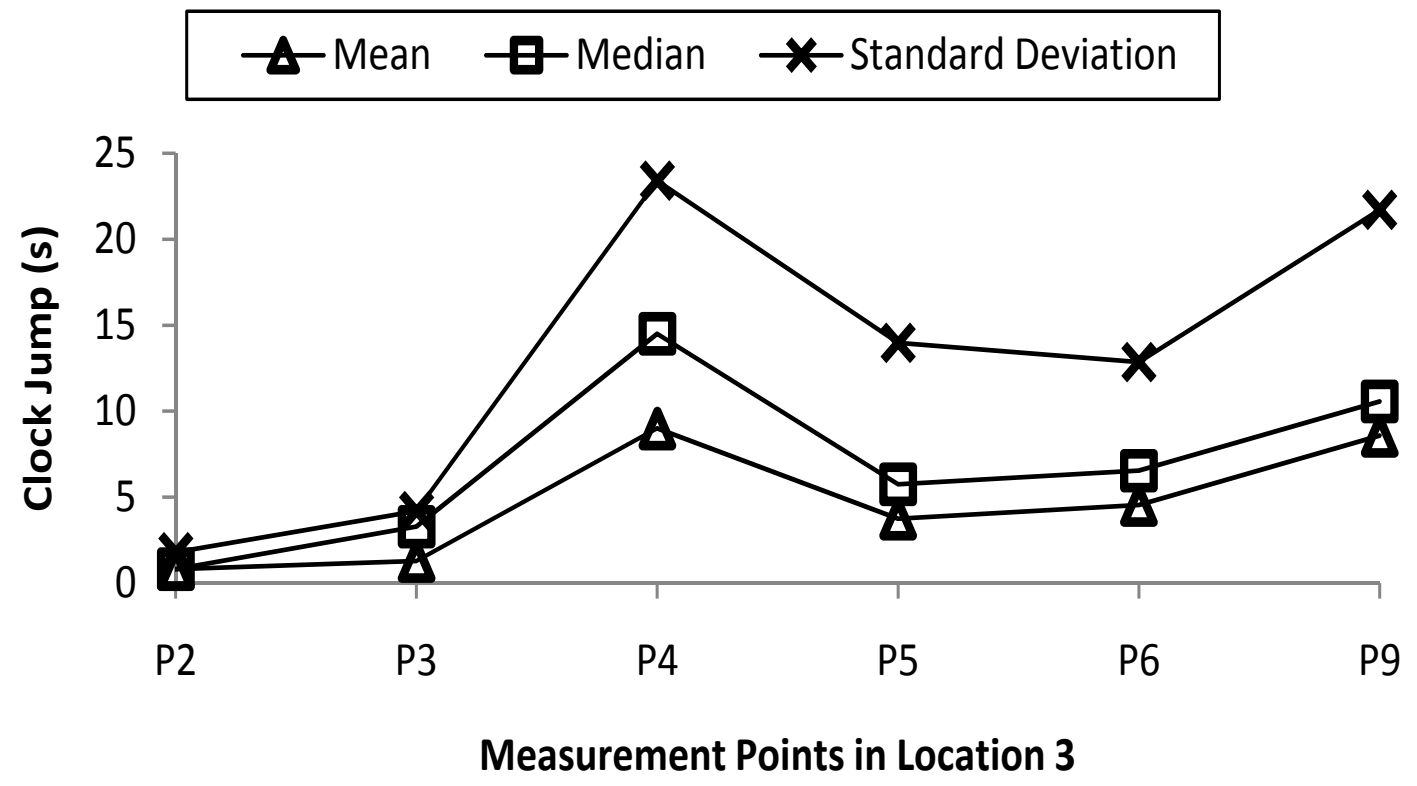

Human Traffic at Location 3

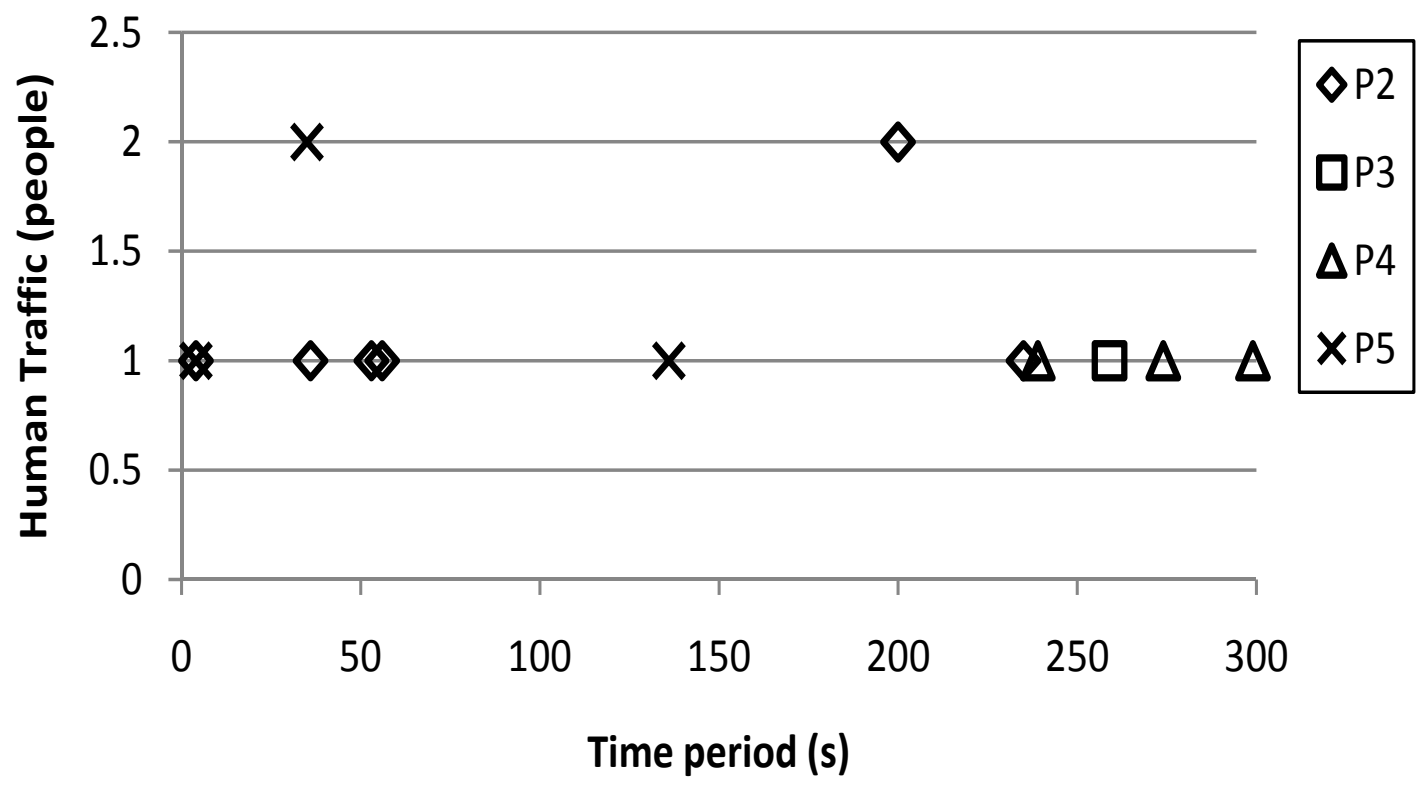

Figure 4.4: Effect of Distance and Human Traffic on Video Streaming Quality in Location 3 


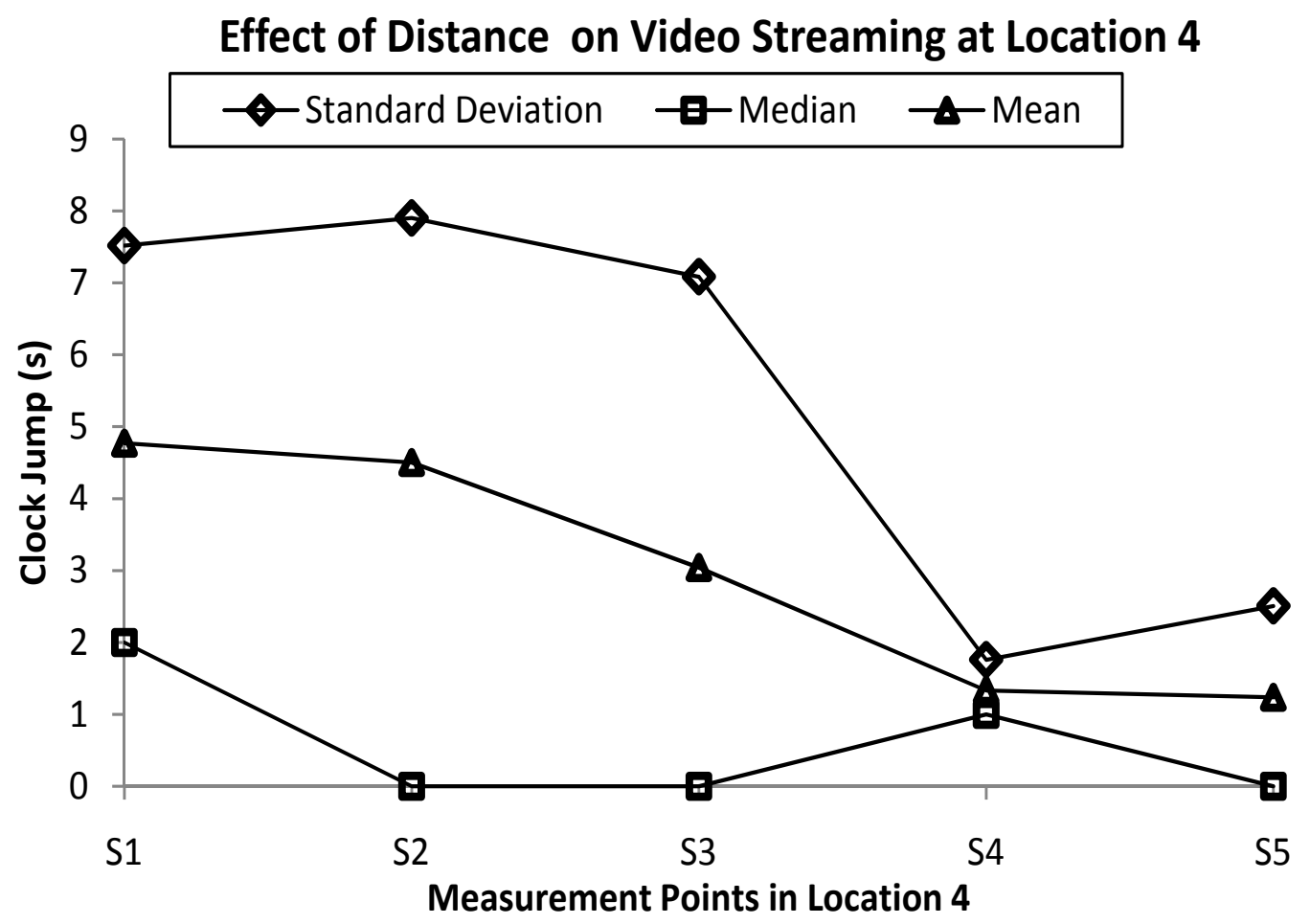

Human Traffic at Location 4

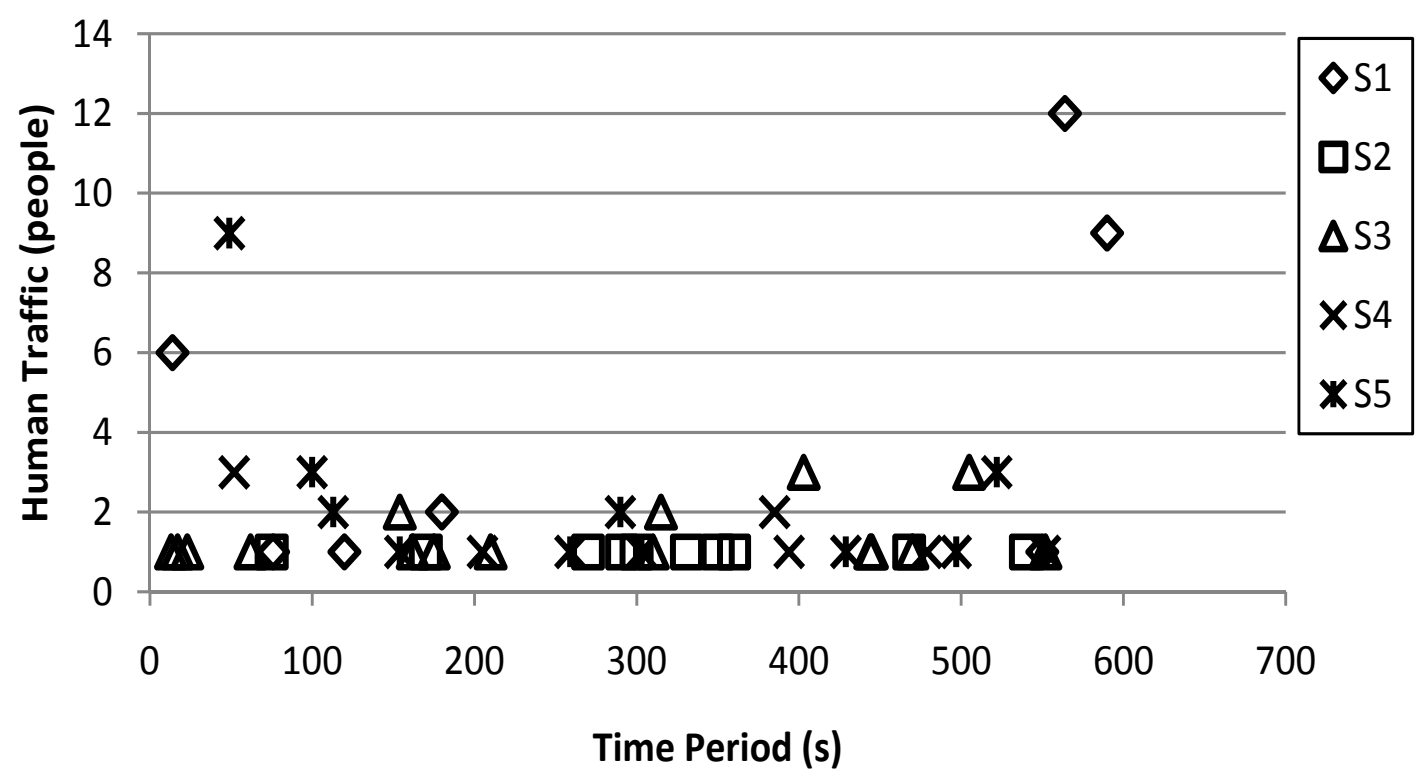

Figure 4.5: Effect of Distance and Human Traffic on Video Streaming Quality in Location 4 

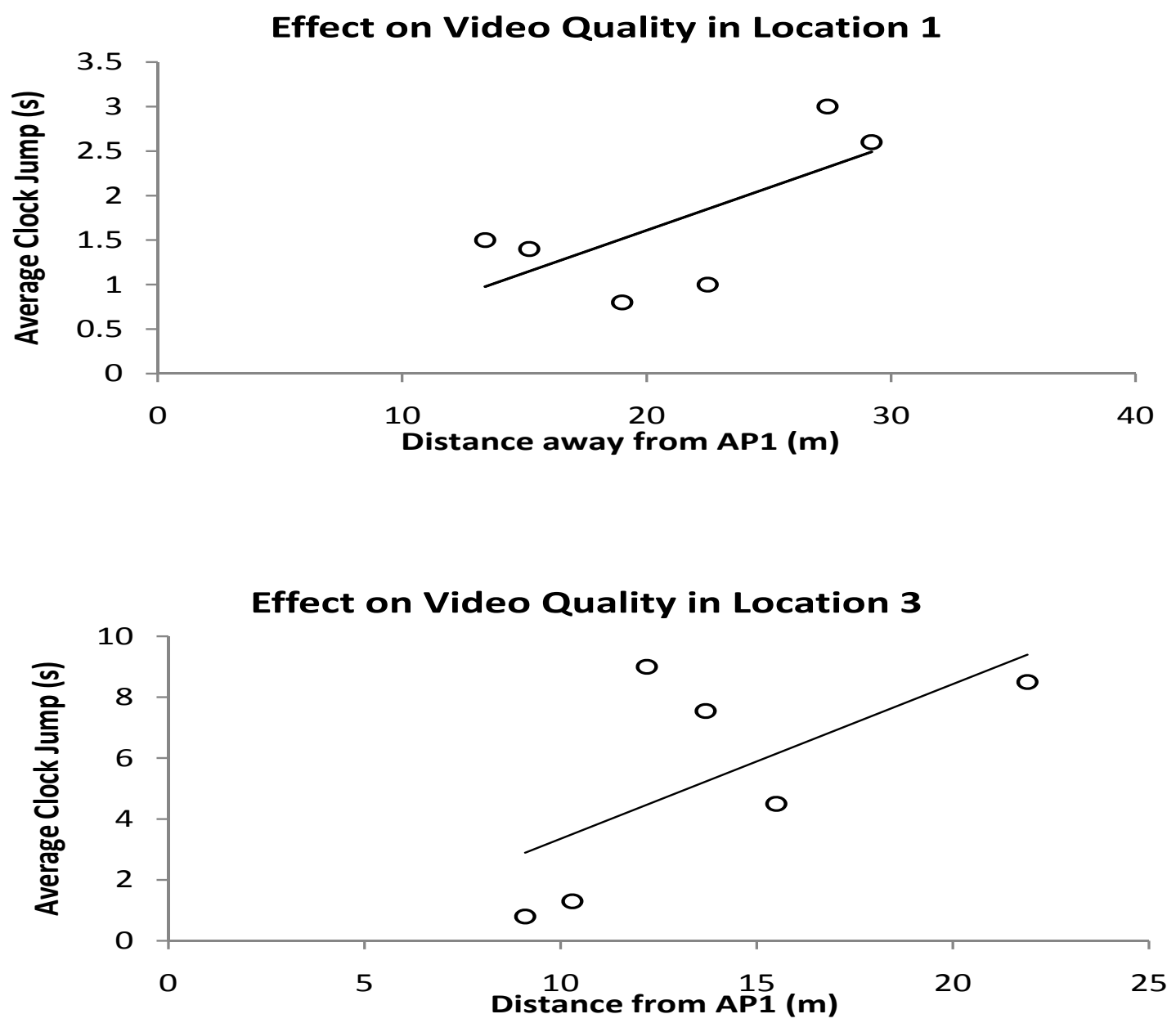

\section{Effect on Video Quality in Location 4}

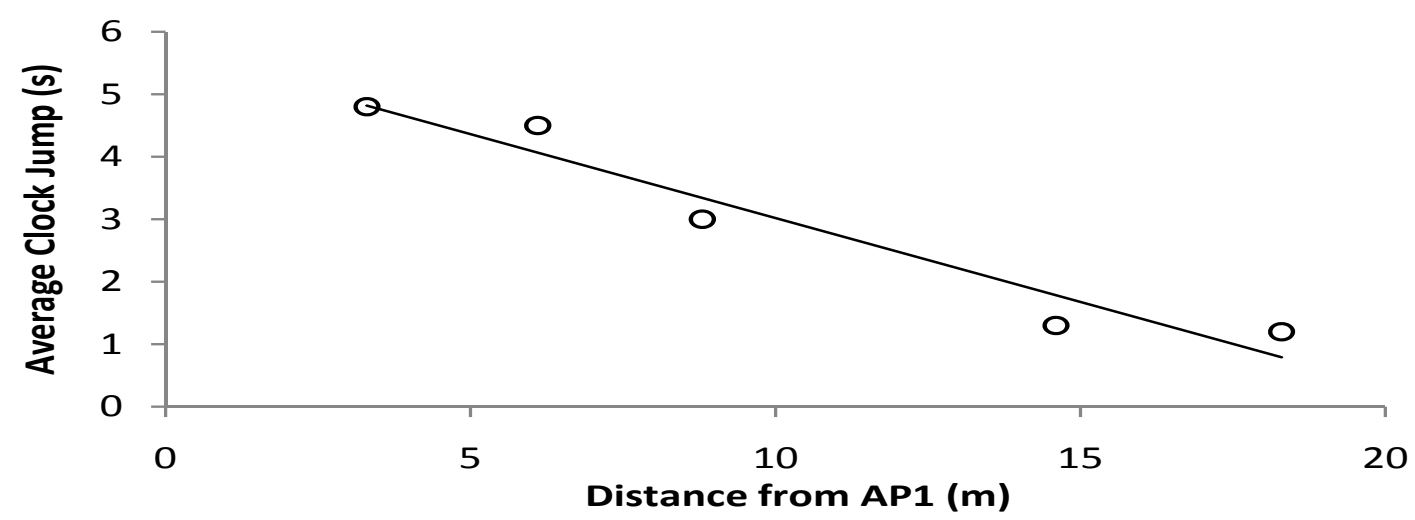

Figure 4.6: Best fit line for the Effect of Distance on Video Streaming Quality in Location 1, 3 and 4 
point, thereby, receiving better video quality.

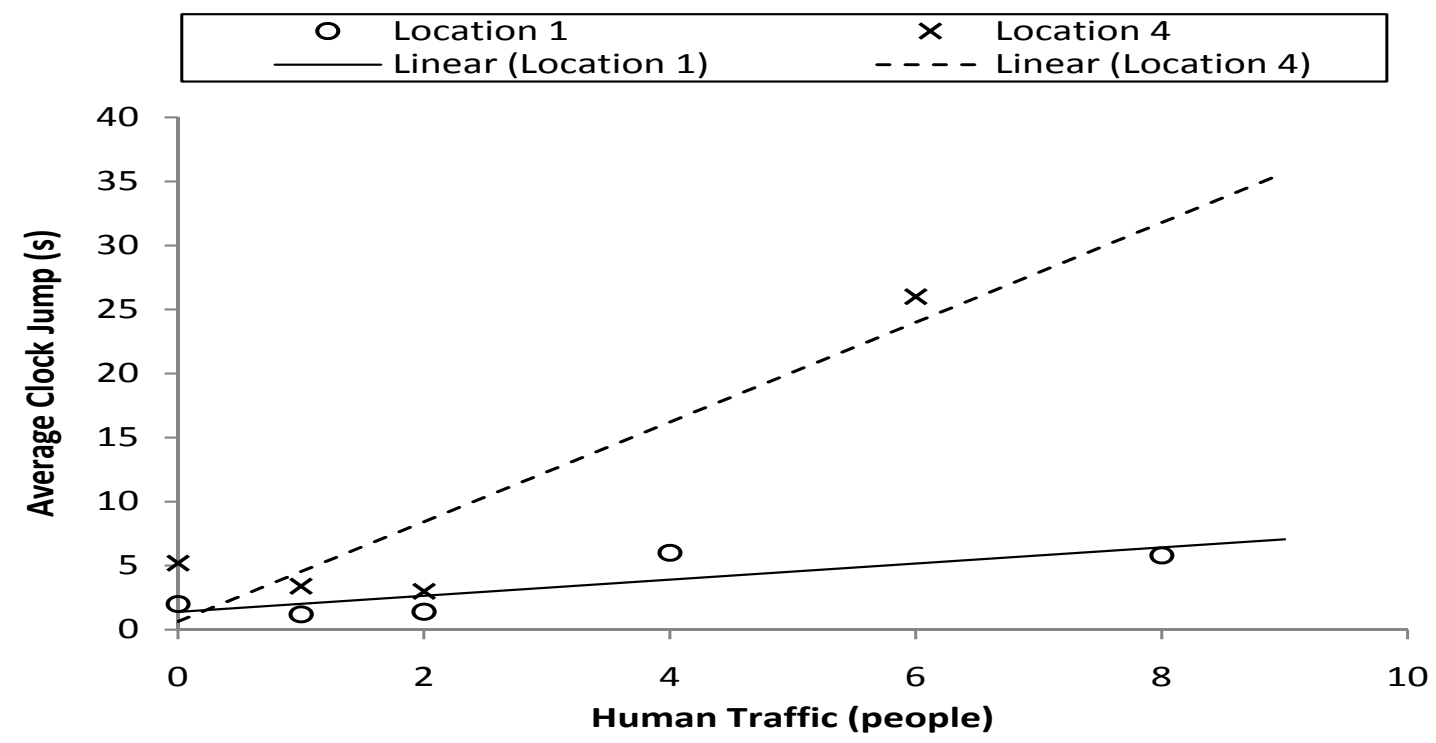

Figure 4.7: Best fit line for the Effect of Human Traffic on Video Streaming Quality in Location 1 and 3

The result for evaluation of human traffic effect on video quality is shown in Figure 4.7 where it demonstrates that with the increase in the number of human traffic in the environment, the higher is the value of average clock jump at that particular location. The larger value in the clock jump indicates that there is a degradation in the quality of the video received at that location.

\subsection{Received Signal Power}

"As the RF wave travels through the environment, with walls, humans, animals and even the air, some of its energy will be lost because of absorption and other RF behaviors like reflection, refraction, diffraction and scattering" [29]. Thus the RF signal strength is said to decrease which indicates that the average received signal power decreases logarithmically with distance [16].

The average received signal power is reported in $\mathrm{dBm}$. This section of the 
chapter describes the received signal strength during the video streaming over $802.11 \mathrm{~b}$ in the presence of human traffic at varying distances and presents analysis on the results obtained.

\subsubsection{Experimental Set-up}

The measurements were taken in Location 1 and Location 3 using the same wireless network already described in Chapter 2. In addition to that, a spectrum analyzer was used to measure the received signal power at the MT during live video streaming over $802.11 \mathrm{~b}$ in the presence of human traffic. The measurement was taken at increasing distances from the access point in all the three locations. The overall layout of the locations of measurement is shown in Figure 2.1. The measurement

was taken during the normal working days and at the time of measurement, the environmental conditions were observed as follows:

- Location 1: This location had more human traffic than the other locations. The fire door towards the end of the hallway was kept closed during the entire time of measurement so as to avoid accessing the second access point, AP2.

- Location 3: This location had less human traffic compared to the other locations and the measurement was without any Bluetooth user in the vicinity of measurement environment.

\subsubsection{Data Measurement and Recording}

The received signal power was measured at increasing distances from AP1 in both the locations. The received signal power was measured at points R1, R2, R3, R4, R5 and R6 in Location 1 and at P1, P2, P4, P6, P8 and P9 in Location 3 during live video streaming over $802.11 \mathrm{~b}$. The distances of all points of measurement are given in Table 4.2 . 
Table 4.2: Distance from AP1 for Signal Power Measurement

\begin{tabular}{|c|c||c|c|}
\hline Location 1 & $\begin{array}{c}\text { Distance } \\
(\mathrm{m})\end{array}$ & Location 3 & $\begin{array}{c}\text { Distance } \\
(\mathrm{m})\end{array}$ \\
\hline \hline R1 & 13.4 & P1 & 8 \\
\hline R2 & 15.2 & P2 & 9.1 \\
\hline R3 & 19 & P3 & 12.2 \\
\hline R4 & 22.5 & P4 & 15.5 \\
\hline R5 & 27.4 & P5 & 20.1 \\
\hline R6 & 29.2 & P6 & 21.9 \\
\hline
\end{tabular}

\subsubsection{Result and Analysis}

The measurements were taken in presence of human traffic at all the points described earlier in both the locations. The first measurement taken in Location 1 was at $\mathrm{R} 1$ which is at a distance of $13.4 \mathrm{~m}$ away from AP1 and the highest received signal power measured was $-60 \mathrm{dBm}$ and the lowest was $-81 \mathrm{dBm}$ measured at a distance of $29.2 \mathrm{~m}$ as shown in Figure 4.8. The highest received signal power measured at Location 3 was $-66.3 \mathrm{dBm}$ and the lowest was $-87.1 \mathrm{dBm}$ at a distance of $8 \mathrm{~m}$ and $21.9 \mathrm{~m}$ away respectively from the access point.

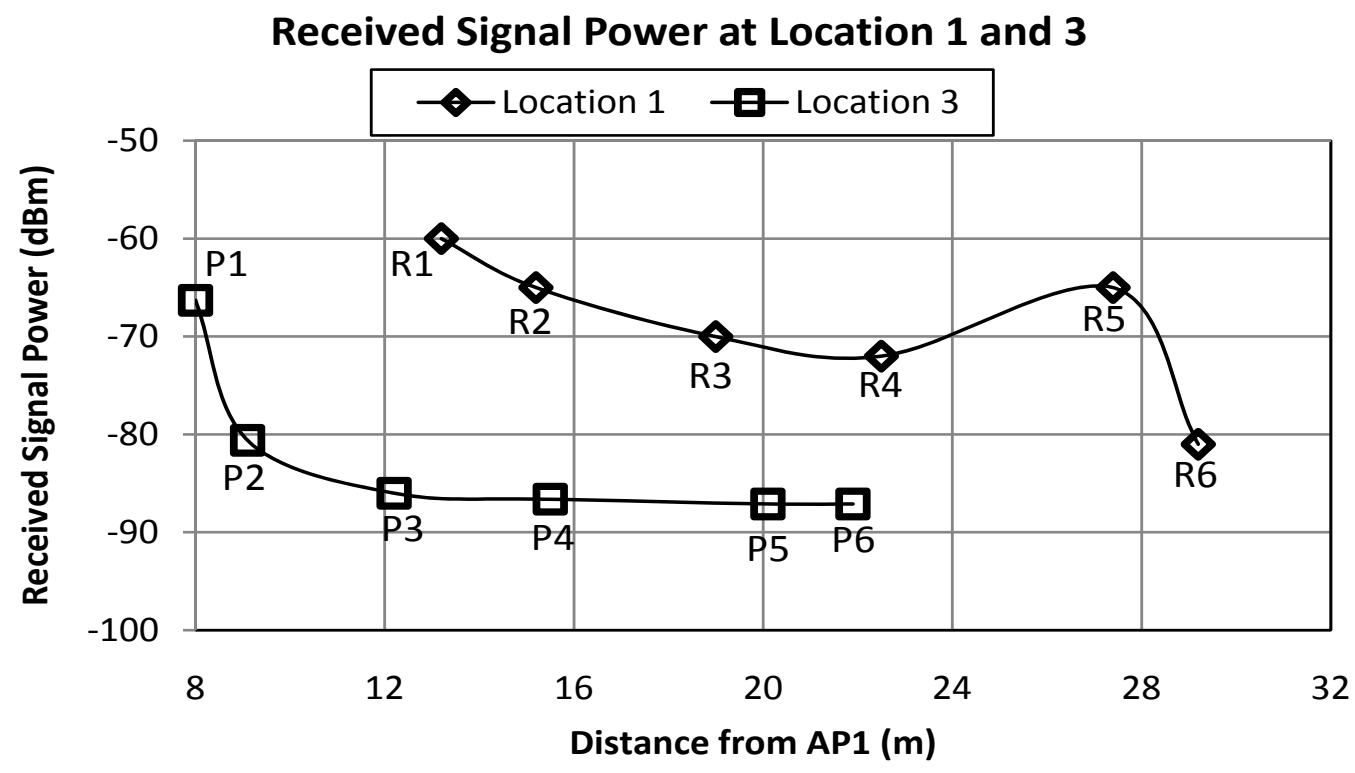

Figure 4.8: Average Received Signal Power at Location 1 and 3 
These measurements were taken in the presence of human traffic and these are shown in Figure 4.9 for both Locations 1 and 3. From the graph, we can see that there was significant human traffic in Location 1 and as the measurement was being taken, seven children and one man walked through the hallway and were in the hallway for 152 seconds. At this particular time of measurement, larger clock jumps were observed in presence of eight people in the hallway. As a result, the average received signal strength at the MT is expected to be lower than the other points but as mentioned earlier in the chapter, there was an active Bluetooth user at the time of measurement. Otherwise, the received signal power decreases as the MT moves further away from the access point as shown in Figure 4.8. 
Human Traffic in Location 1 Affecting Received Signal

Power

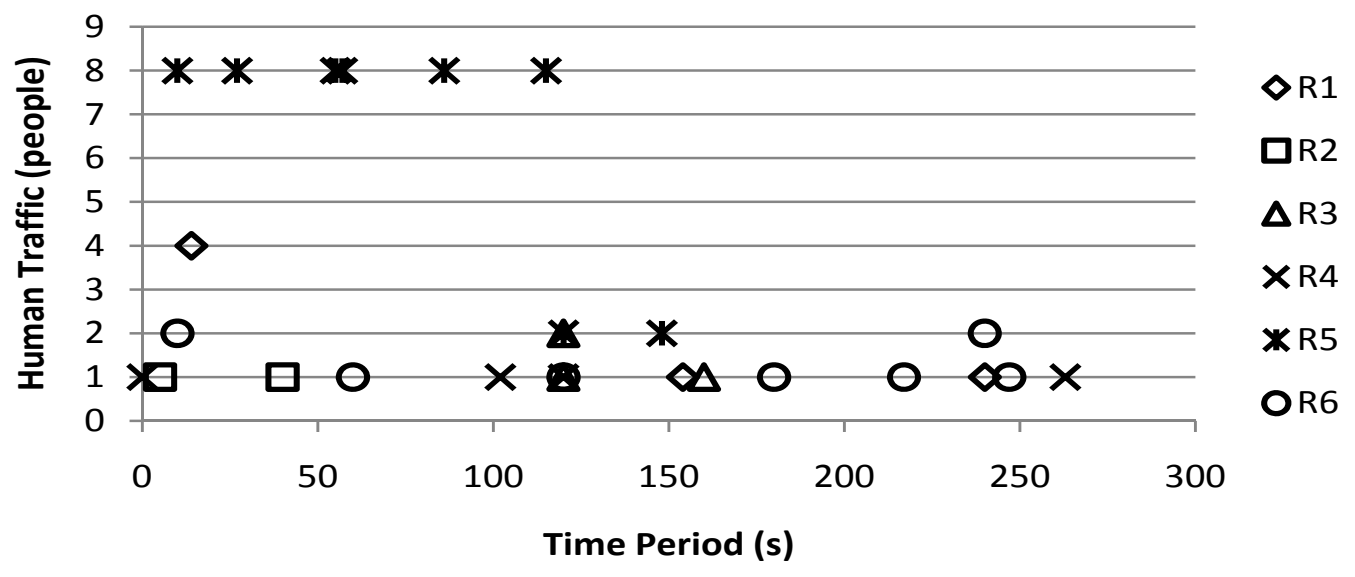

Human Traffic at Location 3 Affecting Received Signal Power

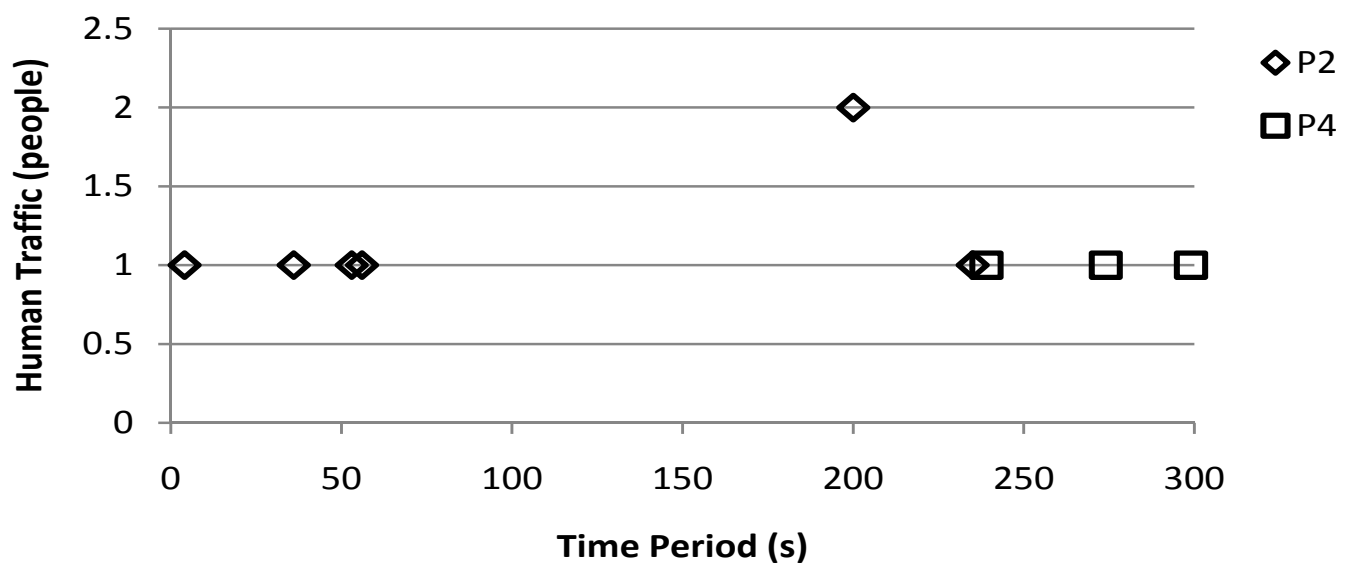

Figure 4.9: Human Traffic in Location 1 and 3 respectively for Received Signal Power Measurement 


\section{Chapter 5}

\section{Bluetooth Analysis}

Bluetooth and Wi-Fi operating in the same ISM frequency band experience interference due to one another when collocated. This mutual interference has been shown through experimental investigations in [30], [31], [32], [33], [34] and [35]. There have been numerous experimental investigations of Wi-Fi performance in the presence of Bluetooth interference and Bluetooth performance in the WLAN environment. This chapter looks into the quality of streamed video across $802.11 \mathrm{~b}$ in the presence of Bluetooth and human traffic, and also studies the performance of Bluetooth in a WLAN environment.

\section{$5.1 \quad$ Impact of Bluetooth on Video Streaming and 802.11b Performance}

Bluetooth uses the same unlicensed frequency band as that of $802.11 \mathrm{~b}$ so it is observed to cause interference in the streaming of video signals over $802.11 \mathrm{~b}$, which leads to the degradation of the quality of streamed video. 


\subsubsection{Experimental Set-up and Measurement}

The measurement network described in Chapter 2 was set up in Location 2 for studying the impact of Bluetooth on video quality and to study Bluetooth performance in the presence of a WLAN environment. Similar to the experimental measurements done in the previous chapter, the Wi-Fi station consists of the MT which is a Dell Laptop with a Wi-Fi PCMCIA card and the Bluetooth device called BT, which is a Palm Treo Smartphone. In the piconet formed, the MT is used as the Bluetooth master whereas the BT is the Bluetooth slave.

The measurements were taken during a normal working day which included human traffic during the data measurement. The measurements were taken in Location 2 and Location 3 as described below:

1. The measurements were first taken at Q1 in Location 2 and P1 in Location 3 with BT switched off and only in the presence of human traffic walking across the measurement environment.

2. The MT was first placed at point Q1 in Location 2 and the measurements were taken. Then BT was placed $0.3 \mathrm{~m}$ away from the MT towards the direction of the access point as shown in Figure 5.1 and switched on for measurement. These measurements were repeated at a distance of $0.9 \mathrm{~m}$ and $1.5 \mathrm{~m}$ towards the direction of the access point and at $0.3 \mathrm{~m}$ and $0.9 \mathrm{~m}$ away from the MT and the access point as shown in Figure 5.2. The measurements were repeated at point Q2 in Location 2. The layout of Location 2 is given in Figure 3.5 in Chapter 3 .

3. Similar measurements were taken in Location 3 at points P1, P2, P3 and P4 which were at a distance of $21 \mathrm{~m}, 23 \mathrm{~m}, 25 \mathrm{~m}$ and $27 \mathrm{~m}$ away from access point AP1, respectively. At each point, BT was switched on and placed at a distance of $0.3 \mathrm{~m}, 3.3 \mathrm{~m}$ and $8.8 \mathrm{~m}$ away from the MT and AP1 for measurement. The 


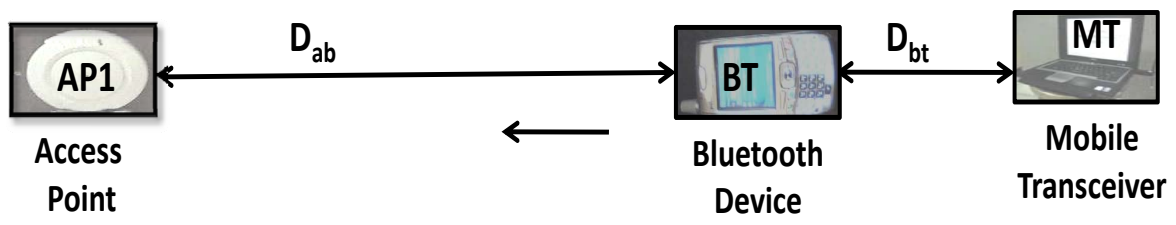

Figure 5.1: BT moving towards AP1 for varying $D_{b t}$

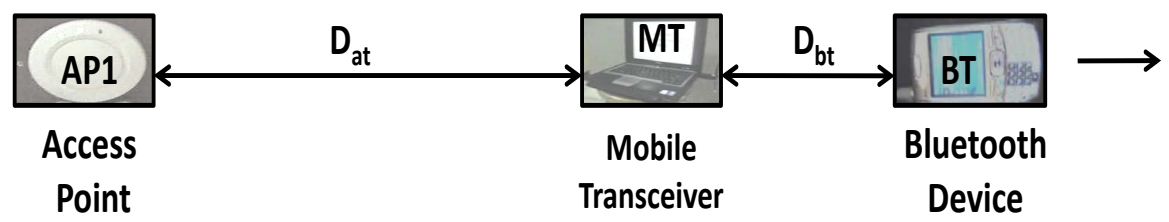

Figure 5.2: BT moving away from AP1 for varying $D_{b t}$

layout of Location 3 is shown in Figure 3.1 in Chapter 3. The first point P1 at this location was identified first for this measurement by observing the quality of streamed video in presence of Bluetooth and was so chosen that any point closer than P1 to AP1 showed similar behavior in the presence of human traffic and Bluetooth.

As discussed in Chapter 4, the measurement points at this location were restricted due to the limited Wi-Fi signal strength and when ever Bluetooth was switched on at a distance more than $31 \mathrm{~m}$, the Wi-Fi connection was lost even without human traffic. The connection was lost sooner in the presence of human traffic in the measurement environment.

\subsubsection{Result and Analysis}

As described in the previous chapter, the measurements were taken in every 5 minutes in the sets of $60 \mathrm{~s}$ for every point in each location. The measurements taken at $\mathrm{P} 1$ in Location 3 is summarized in Table 5.1.

From the Table 5.1, we can observe that the Wi-Fi connection at P1 is lost 
Table 5.1: Video streaming in the presence of Bluetooth at P1 in Location 3

\begin{tabular}{|c|c|c|c|c|}
\hline $\begin{array}{c}\text { Separation } \\
D_{b t} \\
(\mathrm{~m})\end{array}$ & $\begin{array}{c}\text { Time of Arrival } \\
\text { tau }_{a} \\
(\mathrm{~s})\end{array}$ & $\begin{array}{c}\text { Human Traffic } \\
h_{1} \\
(\text { people })\end{array}$ & $\begin{array}{c}\text { Clock Jump } \\
\tau_{j 3} \\
(\mathrm{~s})\end{array}$ & Comment \\
\hline \hline 0 & 1 & 0 & 1 & Bluetooth switched off \\
\hline 0 & 2 & 0 & 1 & Bluetooth switched off \\
\hline 0 & 45 & 1 & 0 & Bluetooth switched off \\
\hline 0 & 47 & 0 & 0 & Wi-Fi connection lost \\
\hline 0.3 & 18 & 0 & 12 & BT connecting \\
\hline 0.3 & 30 & 0 & 2 & Bluetooth connected \\
\hline 0.3 & 50 & 0 & 10 & Wi-Fi connection lost \\
\hline 3.3 & 2 & 0 & 2 & BT connecting \\
\hline 3.3 & 12 & 0 & 5 & BT connected \\
\hline 3.3 & 18 & 0 & 0 & Wi-Fi connection lost \\
\hline 8.8 & 32 & 0 & 2 & BT connected \\
\hline 8.8 & 34 & 0 & 10 & BT still connected \\
\hline 8.8 & 45 & 0 & 4 & Wi-Fi still connected \\
\hline
\end{tabular}

due to human shadowing even though the BT was not switched on. If the BT was switched on next to the MT then it immediately lost Wi-Fi connection. When the BT was placed at a distance of $0.3 \mathrm{~m}$ away from the MT, the video streaming was affected more when the Bluetooth connection was being established. We can observe a few clock jumps during the file transfer between the BT and the MT which shows that the video streaming is being affected by the Bluetooth interference and soon after loses Wi-Fi connection. Similarly, when the BT was placed $3.3 \mathrm{~m}$ away from the MT, the Wi-Fi connection was lost shortly after the Bluetooth connection was established between the MT and the BT. But when the BT was placed at a distance of $8.8 \mathrm{~m}$ away from the MT, although Bluetooth interference affected the quality of streamed video, the MT was still connected to Wi-Fi with continuous video streaming.

Similarly, the Bluetooth and Wi-Fi status for point P2 at a separation of $0.3 \mathrm{~m}$, $3.3 \mathrm{~m}$ and $8.8 \mathrm{~m}$ between the BT and the MT is shown in Table 5.2. The MT is at a distance $23 \mathrm{~m}$ away from the access point and it shows similar results as at point P1. 
Table 5.2: Video streaming in the presence of Bluetooth at P2 in Location 3

\begin{tabular}{|c|c|c|}
\hline $\begin{array}{c}\text { BT-MT Separation } \\
D_{b t} \\
(\mathrm{~m})\end{array}$ & BT Status & Wi-Fi Status \\
\hline \hline 0.3 & Disconnected & Disconnected \\
\hline 3.3 & Connected & Disconnected \\
\hline 8.8 & Connected & Connected but lost the video \\
\hline
\end{tabular}

The Wi-Fi connection is lost shortly after the Bluetooth connection is established between the MT and BT when the BT is placed $0.3 \mathrm{~m}$ and $3.3 \mathrm{~m}$ away from the MT. But when it is placed at $8.8 \mathrm{~m}$ away from the MT, the video signal was lost although it was still connected to Wi-Fi. The result shows the effect of human traffic and distance on quality of streamed video across $802.11 \mathrm{~b}$ in the presence of Bluetooth interference and also agrees with Hautala et al. [36] who have discussed that "the effects of the interference are especially strong when the Bluetooth and WLAN devices coexist in the same machine."

\subsection{Impact of Human Traffic on Bluetooth Perfor- mance}

As referenced earlier, there have been many experimental investigations done to study Bluetooth performance in a Wi-Fi environment. Vilovic et al. [37] have presented simulation results showing that Bluetooth gets affected by $802.11 \mathrm{~b}$ interference and causes degradation in the Bluetooth performance due to $802.11 \mathrm{~b}$ interference. Keller et al. [26] have shown through experimental results that Bluetooth system throughput is significantly reduced in the presence of WLAN interference and the situation is worse when the interference appears closer to the Bluetooth slave of the piconet. This chapter looks into the Bluetooth system performance in the presence of human shadowing through video streaming across 802.11b. 
As Location 3 has limited Wi-Fi signal strength and especially with the Bluetooth device switched on, limited data were recorded at this location. The measurements were done at the four points, P1, P2, P3 and P4 described earlier in this chapter.

\subsubsection{Experimental Set-up and Measurement}

The measurement was to be taken from all the four locations described in the previous chapters, but Location 1 and Location 4 had a few Bluetooth users in the vicinity of the measurements; thus the measurements were taken in Location 2 and Location 3. Location 3 having weak signal strength, lost the Wi-Fi connection whenever the BT was switched on. Therefore, most of the measurements were taken in Location 2 and a limited data was measured in Location 1. The layout of Location 2 and Location 3 is given in Figure 3.5 and Figure 3.1, respectively, in Chapter 3.

The MT was placed at location Q1 which was at a distance of $20 \mathrm{~m}$ from the access point, AP1 and the BT was placed at a distance of $0.3 \mathrm{~m}$ from the MT during the entire time of measurement. The measurement was taken during normal working hours in the presence of human traffic. The measurement network was set up at Q1 and readings were recorded in every 60 seconds for 30 minutes. The file transferred within the piconet was a JPEG image of size $29 \mathrm{kB}$ and dimensions 240 by 320 . The measurement was repeated at Q2 in the same location by keeping the fire door open for Wi-Fi network coverage. Whenever the Bluetooth connection was established between the MT and the BT, the Wi-Fi connection was lost, and so the MT had to be taken back to $\mathrm{Q} 1$ to reconnect to the Wi-Fi.

\subsubsection{Result and Analysis}

The result of the measurement taken at Q1 basically gives the file transfer time using Bluetooth in the presence of human traffic. From Table 5.3, we can clearly 
Table 5.3: Human Traffic Effect on Bluetooth System Performance at Q1

\begin{tabular}{|c|c|c|}
\hline $\begin{array}{c}\text { Time of Arrival } \\
\tau_{a} \\
(\mathrm{~s})\end{array}$ & $\begin{array}{c}\text { Human Traffic } \\
h_{1} \\
\text { (people) }\end{array}$ & $\begin{array}{c}\text { Time Taken for File Transfer } \\
\tau_{f} \\
(\mathrm{~s})\end{array}$ \\
\hline \hline 1 & 1 & 10 \\
\hline 45 & 1 & 11 \\
\hline 75 & 1 & 11 \\
\hline 144 & 1 & 11 \\
\hline 193 & 1 & 10 \\
\hline 240 & 1 & 10 \\
\hline 246 & 1 & 9 \\
\hline 285 & 1 & 10 \\
\hline 329 & 8 & 45 \\
\hline 359 & 1 & 11 \\
\hline
\end{tabular}

observe that the file transmission time for the $\mathrm{BT}$ in the absence of human traffic is found to be around 9 to 11 seconds. Although, the same file was transferred in less than $5 \mathrm{~s}$ with or without human traffic at Location 4 . As already discussed, Location 2 has a strong Wi-Fi signal, thus human traffic of one person or two people seems to have no effect on the quality of video streaming across $802.11 \mathrm{~b}$. At one time, when the human traffic was 8 people, the time taken to transfer the file was 45 seconds. Thus, the file transmission seems to take a longer time in the presence of large amounts of human traffic, even in an area with strong signal strength. There was an interesting observation during the measurement, when 25 people walked through the corridor in a line during the file transfer via Bluetooth and the file could not be delivered to the MT.

The result of data measured when the BT is switched on in Location 3 is summarized in Table 5.4. From Table 5.4, we can observe that the MT loses the WiFi connection at $\mathrm{P} 3$ and $\mathrm{P} 4$ which are at $25 \mathrm{~m}$ and $27 \mathrm{~m}$ away from the access point, respectively. It was observed during the measurement that no matter how far the BT was placed from the MT, within the Bluetooth range, the Bluetooth connection between the BT and the MT could not be established. Even at P1 and P2, if the 
Table 5.4: Bluetooth Performance in WLAN Environment in Location 3

\begin{tabular}{|c|c|c|c|c|}
\hline Location & $\begin{array}{c}\text { Separation } \\
\text { between BT and MT } \\
D_{b t} \\
(\mathrm{~m})\end{array}$ & $\begin{array}{c}\text { Clock jump } \\
\text { start time } \\
\tau_{j 1} \\
(\mathrm{~s})\end{array}$ & $\begin{array}{l}\text { Clock Jump } \\
\qquad \begin{array}{c}\tau_{j 3} \\
(\mathrm{~s})\end{array}\end{array}$ & Comment \\
\hline $\mathrm{P} 1$ & 0 & 0 & $\overline{0}$ & Wi-Fi Lost \\
\hline P1 & 0.3 & $\begin{array}{l}18 \\
30 \\
60\end{array}$ & $\begin{array}{c}12 \\
2 \\
0\end{array}$ & $\begin{array}{c}\text { BT connected } \\
\text { BT still connected } \\
\text { Wi-Fi Lost }\end{array}$ \\
\hline P1 & 3.3 & $\begin{array}{c}2 \\
12 \\
18\end{array}$ & $\begin{array}{l}2 \\
5 \\
0\end{array}$ & $\begin{array}{c}\text { BT connected } \\
\text { BT still connected } \\
\text { Wi-Fi Lost }\end{array}$ \\
\hline P1 & 8.8 & $\begin{array}{l}32 \\
34 \\
45\end{array}$ & $\begin{array}{c}2 \\
10 \\
4\end{array}$ & $\begin{array}{c}\text { BT connected } \\
\text { BT still connected } \\
\text { Video signal Lost }\end{array}$ \\
\hline $\mathrm{P} 2$ & 0 & 0 & 0 & Wi-Fi Lost \\
\hline $\mathrm{P} 2$ & 0.3 & $\begin{array}{c}1 \\
10\end{array}$ & $\begin{array}{l}0 \\
0\end{array}$ & $\begin{array}{l}\text { BT connected } \\
\text { Wi-Fi lost }\end{array}$ \\
\hline & 3.3 & $\begin{array}{l}12 \\
30\end{array}$ & $\begin{array}{c}12 \\
0\end{array}$ & $\begin{array}{l}\text { BT connected } \\
\text { Wi-Fi Lost }\end{array}$ \\
\hline $\mathrm{P} 2$ & 8.8 & $\begin{array}{l}1 \\
5\end{array}$ & $\begin{array}{l}0 \\
0\end{array}$ & $\begin{array}{c}\text { BT connected } \\
\text { Video signal Lost }\end{array}$ \\
\hline P3 & $0,0.3,3.3,8.8$ & 0 & 0 & Wi-Fi Lost \\
\hline $\mathrm{P} 4$ & $0,0.3,3.3,8.8$ & 0 & 0 & Wi-Fi Lost \\
\hline
\end{tabular}


BT is placed next to the MT, Wi-Fi connection is lost due to the strong Bluetooth interference which is in agreement with what Hautala et al. [36] have mentioned. But when the separation between the BT and the MT is increased, the Bluetooth connection is established successfully although Wi-Fi is lost shortly afterwards when separated at $3.3 \mathrm{~m}$, only the video signal is lost when placed at $8.8 \mathrm{~m}$ separation. It was observed that the file could not be transferred within the piconet except when the separation was $8.8 \mathrm{~m}$ between the BT and the MT at P1 and P2. Thus, Bluetooth performance is highly affected by the WLAN environment and the intensity of human traffic depending on the Wi-Fi signal strength in that location. 


\section{Chapter 6}

\section{Conclusion}

\subsection{Summary of Work Done}

Initially, wireless networks were designed for data communication but with time and advancement, wireless networks have come to be most popularly used in multimedia and various other integrations of signals. This thesis looks into the quality of video streaming over $802.11 \mathrm{~b}$ in a normal working environment in the presence of fading due to human shadowing and Bluetooth interference.

In Chapter 3 of this thesis, the link performance of $802.11 \mathrm{~b}$ was described during video streaming where it was shown that the quality of video degraded as the MT was moved further away from the access point. There were regions discovered such as the VCR where the video streaming could be connected and video signals could be received continuously, and the VLR where the video could be received but it was unable to stream continuous video. It was also shown that the human traffic in the measurement environment affected the quality of video in the VCR and beyond which, it affected the connectivity to Wi-Fi.

The impact of human shadowing on the quality of the video signal was evaluated in Chapter 4 through experimental measurements in a normal working environ- 
ment. An analysis was shown of the effect on video quality in the presence of human traffic in different locations with varying environmental conditions. This effect was also evaluated by measuring the received signal power at all points of measurement in the environment where the results show that the signal strength decreases with the increase in distance from the access point and due to fading.

The collocation of a Bluetooth system with a WLAN system seems to impair the performance of both systems, especially when the master of the piconet is within the WLAN. From the results shown in Chapter 5, it was observed that the Bluetooth performance was affected when there was a higher amount of human traffic. Also, the video quality was observed to degrade as the separation between the MT and BT was increased.

If WLANs are used, the problems due to fading caused by circumstances of human traffic and Bluetooth must be allowed and understood in order to keep to a minimum the exposure of humans to RF signals.

\subsection{Future Work and Recommendations}

In this thesis, the quality of video signal streamed over $802.11 \mathrm{~b}$ was measured in the presence of Bluetooth interference and fading due to human traffic, these measurements could be evaluated in the presence of other 802.11 devices which operate in the same ISM band and might cause co-channel interference affecting the video quality. In this research, continuous live video streaming could be received only within VCR and so as to improve the video quality, the range has to be increased further which could be done by following the suggestions:

1. Study the indoor environment properly before planning the placement of access points for good network coverage at all locations of the building. For example, an open area like the Head Rest could have an access point at that location 
instead of being placed in another room next to it with two large vending machines standing next to the common wall.

2. Add only enough access points to increase the weak signal strengths, in areas depending on their location and the density of users.

3. Plan to have users within the VCR for quality video streaming over 802.11b.

4. Improving the environment so as to mitigate Bluetooth interference and human shadowing effects. For example, readjusting the antennas on the raised ceilings and avoiding points above raised ceilings that may start emitting spurious radiation, or relocating large metallic objects obstructing the radio propagation path if possible, or using passive repeaters described by Huang et al. [38] on walls for improving radio coverage over particular locations like Head Rest or open spaces such as a library.

In this research work, most of the measurements had human traffic along the hallway in the measurement environment which affected the video quality and in an area with weak Wi-Fi coverages; reliable video quality could be received only within the VCR. During the measurements, it was observed in Location 3 that two people walked into the measurement environment and stood still, in between the access point AP1, and the mobile transceiver, MT which led to loss of video signal. The effect of human body shadowing should be investigated in detail for such a situation and an approximate path loss could be determined for reliable video streaming over 802.11b. 


\section{References}

[1] S. Abukharis and T. O'Farrell, "MPEG-2 video streaming over IEEE 802.11g WLAN in the presence of bluetooth interference," Fifth IEEE International Conference on 3G Mobile Communication Technologies, (London, UK), pp. 579-583, Oct. 18-20 2004.

[2] H. Linna and Y. Wei, "Interference evaluation of Bluetooth and IEEE 802.11b systems," Proceedings of the 4 th International Conference on Microwave and Millimeter Wave Technology, (Beijing, China), pp. 931-934, Aug. 2004.

[3] A. Messier, J. Robinson, and K. Pahlavan, "Performance monitoring of a wireless campus area network," Proceedings of 22nd Annual Conference on Local Computer Networks, (Washington DC, USA), pp. 232-238, Nov. 2-5 1997.

[4] N. Sarkar and K. Sowerby, "Wi-fi performance measurements in the crowded office environment: a case study," International Conference on Communication Technology, (Colorado, USA), pp. 1-4, Nov. 2006.

[5] J. Jo and N. Jayant, "Measurement and analysis of the channel characteristics of an in-building wireless network," 54th ARFTG Conference Digest-Spring, (Atlanta, USA), vol. 36, pp. 1-6, Dec. 1999.

[6] D. Eckhardt and P. Steenkiste, "Measurement and analysis of the error characteristics of an in-building wireless network," in Proceedings of the SIGCOMM '96 
Symposium on Communications Architectures and Protocols,(New York, USA), pp. 243-254, Aug. 1996.

[7] F. Villanese, N. Evans, and W. Scanlon, "Pedestrian-induced fading for indoor channels at 2.45, 5.7 and $62 \mathrm{GHz}, "$ 52nd IEEE Vehicular Technology Conference, (Boston, USA), vol. 1, pp. 43-48, Sept. 24-28 2000.

[8] M. Varshney and R. Bagrodia, "Performance implication of environmental mobility in wireless networks," INFOCOM 200\%, 26th IEEE International Conference on Computer Communications, (Alaska, USA), pp. 767-775, May 2007.

[9] Radiation Protection Bureau, Limits of Human Exposure to Radio Frequency Electromagnetic Fields in the Frequency Range from 3 kHz to 300 GHz: Safety Code 6. Health Protection Branch, Public Works and Government Services, Health Canada, 1999.

[10] S. Hanna, "On human exposure to radio-frequency fields around transmit radio sites," IEEE 49th Vehicular Technology Conference, (Texas, USA), vol. 2, pp. 1589-1593, July 1999.

[11] P. Bobbie and A. Yussif, "Modeling and simulation of IEEE 802.11 Wireless-LAN and Bluetooth Piconet Range Interference," Proceedings on Communications, Internet and Information technology, (Saint Thomas, USVI), vol. 1, pp. 44-49, 2004.

[12] J. Khan, J. Wall, and M. Rashid, "Bluetooth-based wireless personal area network for multimedia communication," Proceedings on The First IEEE International Workshop on Electronic Design, Test and Applications, (Beijing, China), pp. $47-51,2002$. 
[13] J. del Prado and S. Choi, "Experimental study on coexistence of 802.11b with alien devices," 54th Fall Vehicular Technology Conference, (New Jersey, USA), vol. 2, pp. 977-981, 2001.

[14] B. Miller and C. Bisdikian, Bluetooth Revealed: The Insider's Guide to An Open Specification for Global Wireless Communication. Upper Saddle River, NJ, US: Prentice Hall Inc., 2001.

[15] C. Chow and H. Ishii, "Enhancing real-time video streaming over mobile ad hoc networks using multipoint-to-point communication," Comput. Commun., vol. 30, no. 8, pp. 1754-1764, 2007.

[16] T. S. Rappaport, WIRELESS COMMUNICATION: Principles and Practice. Delhi, India: Pearson Education Inc., 2002.

[17] Y. Yamaguchi, T. Abe, and T. Sekiguchi, "Radio propagation characteristics in underground streets crowded with pedestrians," IEEE Transactions on Electromagnetic Compatibility, vol. 30, pp. 130-136, May 1988.

[18] J. LeBel and P. Melancon, "The development of a comprehensive indoor propagation model," IEEE International Symposium on Personal, Indoor and Mobile Radio Communications, (London, UK), pp. 75-79, Sept. 23-25 1991.

[19] R. Valenzuela, O. Landron, and D. Jacobs, "Estimating local mean signal strength of indoor multipath propagation," IEEE Transactions on Vehicular Technology, vol. 46, pp. 203-212, Feb. 1997.

[20] S. Seidel and T. Rappaport, "914 MHz path loss prediction models for indoor wireless communications in multifloored buildings," IEEE Transactions on Antennas and Propagation, vol. 40, pp. 207-217, Feb. 1992.

[21] S. Seidel, T. Rappaport, M. Feuerstein, K. Blackard, and L. Grindstaff, "The impact of surrounding buildings on propagation for wireless in-building personal 
communications system design," 42nd IEEE Vehicular Technology Conference, (Denver, Colorado), pp. 814-818 vol.2, May 1992.

[22] R. Ganesh and K. Pahlavan, "Statistics of short time variations of indoor radio propagation," IEEE International Conference on Communications, (Chicago, USA), vol. 1, pp. 1-5, June 1991.

[23] M. Panjwani, A. Abbott, and T. Rappaport, "Interactive computation of coverage regions for wireless communication in multifloored indoor environments," IEEE Journal on Selected Areas in Communications, vol. 14, pp. 420-430, Apr. 1996.

[24] K. Doraiswamy, L. Merugu, and B. Jinaga, "Ground conduction enhancing GSM air interface performance in ground floor and practical measurements," 24th Biennial Symposium on Communications, (Ontario, Canada), pp. 247-252, June 2008.

[25] D. Hawbaker and T. Rappaport, "Indoor wideband radiowave propagation measurements at $1.3 \mathrm{GHz}$ and $4.0 \mathrm{GHz}$," Electronics Letters, vol. 26, pp. 1800-1802, Oct. 1990.

[26] T. Keller and J. Modelski, "Experimental results of testing interferences in 2.4 GHz ISM band," 33rd European Microwave Conference, (Munich, Germany), vol. 3, pp. 1043-1046, Oct. 2003.

[27] S. Obayashi and J. Zander, "A body-shadowing model for indoor radio communication environments," IEEE Transactions on Antennas and Propagation, vol. 46, pp. 920-927, June 1998.

[28] K. Pahlavan, P. Krishnamurthy, and A. Beneat, "Wideband radio propagation modeling for indoor geolocation applications," IEEE Communications Magazine, vol. 36, pp. 60-65, Apr. 1998. 
[29] T. Carpenter, Wireless \# Certification Official Study Guide (Exam PWO-050). New York, USA: McGraw-Hill Companies, 2006.

[30] M. Shoemake, "Wi-fi (IEEE 802.11b) and Bluetooth: Coexistence issues and solutions for the $2.4 \mathrm{GHz}$ ISM band," Tech. Rep. Version 1.1, Texas Instruments, Texas, USA, Feb. 2001.

[31] Mobilian Corporation, "Wi-Fi (802.11b) and Bluetooth: An examination of coexistence approaches," Tech. Rep. 2, Mobilian Corporation, Oregon, USA, 2001.

[32] A. Conti, D. Dardari, G. Pasolini, and O. Andrisano, "Bluetooth and IEEE 802.11b coexistence: analytical performance evaluation in fading channels," IEEE Journal on Selected Areas in Communications, vol. 21, pp. 259-269, Feb. 2003.

[33] C. Chiasserini and R. Rao, "Performance of IEEE 802.11 WLANs in a Bluetooth environment," IEEE Wireless Communications and Networking, (Chicago, USA), vol. 1, pp. 94-99, 2000.

[34] J. Lansford, A. Stephens, and R. Nevo, "Wi-fi (802.11b) and Bluetooth: enabling coexistence," IEEE Network, vol. 15, pp. 20-27, Sept. 2001.

[35] B. Zhen, Y. Kim, and K. Jang, "The analysis of coexistence mechanisms of Bluetooth," 55th IEEE Vehicular Technology Conference, (Birmingham, USA), vol. 1, pp. 419-423, 2002.

[36] T. Hautala, I. Suliman, J. Lehtomaki, and T. Saarinen, "Performance evaluation of videostreaming on a heterogenous multihop mobile network," 59th IEEE Vehicular Technology Conference, (Milan, Italy), vol. 5, pp. 2744-2747, May 2004.

[37] I. Vilovic and B. Zovko-Cihlar, "Performance analysis of wireless network using Bluetooth and IEEE 802.11 devices," Proceedings on 46 th International Symposium on Electronics in Marine, (Zadar, Croatia), pp. 235-240, June 2004. 
[38] Y. Huang, N. Yi, and X. Zhu, "Investigation of using passive repeaters for indoor radio coverage improvement," IEEE Antennas and Propagation Society International Symposium, (California, USA), vol. 2, pp. 1623-1626, June 2004. 


\section{Appendix A}

\section{Signal Level}

\section{A.1 Signal Level at All Points of Location}

The four locations had varying signal strengths which were indicated on the wireless network signal level indicator in the Dell Latitude Laptop identified as the MT in this thesis. The level of signal strength observed at the four locations was recorded in Table A.1. The columns in Table A.1 are explained as follows:

1. Column 1 represents the location on the D level in Head Hall where the measurements were taken.

2. Column 2 identifies measurement points in the four locations.

3. Column 3 shows the distance of a measurement point from the access point, $\mathrm{AP} 1$, in metres.

4. Column 4 shows the level of Wi-Fi signal strength in number of bars ranging from 1 to 5 corresponding to the signal strength at that particular measurement point, with 5 bars indicating the strongest signal. 
Table A.1: Signal Strength Levels at all Locations

\begin{tabular}{|c|c|c|c|}
\hline Location & Point Name & $\begin{array}{l}\text { Point Distance } \\
(\mathrm{m})\end{array}$ & $\begin{array}{l}\text { Signal Strength } \\
\text { (bars) }\end{array}$ \\
\hline 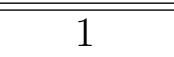 & $\overline{\mathrm{R} 1}$ & 13.4 & $\begin{array}{ll}2 \\
\end{array}$ \\
\hline 1 & $\mathrm{R} 2$ & 15.2 & 2 \\
\hline 1 & R3 & 19 & 2 \\
\hline 1 & $\mathrm{R} 4$ & 22.5 & 2 \\
\hline 1 & R5 & 27.4 & 2 \\
\hline 1 & R6 & 29.2 & 2 \\
\hline 2 & Q1 & 20 & 3 or 4 \\
\hline 2 & Q2 & 24.4 & 1 (if connected) \\
\hline 2 & Q3 & 26.5 & Unable to connect Wi-Fi \\
\hline 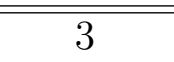 & $\overline{\mathrm{P} 1}$ & 8 & 2 \\
\hline 3 & $\mathrm{P} 2$ & 9.1 & 1 \\
\hline 3 & P3 & 10.3 & 1 \\
\hline 3 & $\mathrm{P} 4$ & 12.2 & 1 \\
\hline 3 & $\mathrm{P} 5$ & 13.7 & 1 \\
\hline 3 & P6 & 15.5 & 1 \\
\hline 3 & $\mathrm{P} 7$ & 19 & 1 \\
\hline 3 & P8 & 20.1 & 1 \\
\hline 3 & P9 & 21.9 & 1 \\
\hline 3 & P10 & 23.2 & 1 \\
\hline 3 & P11 & 26.5 & 1 \\
\hline 3 & P12 & 27.7 & 1 \\
\hline 3 & P13 & 32 & Unable to connect Wi-Fi \\
\hline$\overline{\overline{4}}$ & $\overline{\mathrm{S} \text { S1 }}$ & 3.3 & 4 or 5 \\
\hline 4 & $\mathrm{~S} 2$ & 6.1 & 4 or 5 \\
\hline 4 & S3 & 8.8 & 4 or 5 \\
\hline 4 & $\mathrm{~S} 4$ & 14.6 & 4 or 5 \\
\hline 4 & S5 & 18.3 & 4 or 5 \\
\hline
\end{tabular}




\section{Vita}

Candidate's full name: Karma Kelzang Eudon

University Attended: University of New Brunswick

Fredericton, NB, Canada

2007-2008, M.Sc.E. in Electrical Engineering

Vellore Institute of Technology, India

2000-2004, B.E. in Electrical and Electronics

Engineering

Work Experience: $\quad$ Associate Lecturer

College of Science and Technology, Bhutan

2005-2007, Department of Electrical

Engineering 